\title{
Flood hazard assessment for extreme flood events
}

\author{
Davor Kvočka ${ }^{1} \cdot$ Roger A. Falconer ${ }^{1} \cdot$ Michaela Bray $^{1}$
}

Received: 14 April 2016/Accepted: 24 July 2016/Published online: 30 July 2016

(C) The Author(s) 2016. This article is published with open access at Springerlink.com

\begin{abstract}
Climate change is expected to result in an increase in the frequency and intensity of extreme weather events. In turn, this will result in more frequent occurrences of extreme flood events, such as flash flooding and large-scale river flooding. This being the case, there is a need for more accurate flood risk assessment schemes, particularly in areas prone to extreme flooding. This study investigates what type of flood hazard assessment methods should be used for assessing the flood hazard to people caused by extreme flooding. Two flood hazard assessment criteria were tested, namely: a widely used, empirically derived method, and recently introduced, physically based and experimentally calibrated method. The two selected flood hazard assessment methods were: (1) validated against experimental data, and (2) used to assess flood hazard indices for two different extreme flood events, namely: the 2010 Kostanjevica na Krki extreme river flood and the 2007 Železniki flash flood. The results obtained in this study suggest that in the areas prone to extreme flooding, the flood hazard indices should be based on using the formulae derived for a mechanics-based analysis, as these formulations consider all of the physical forces acting on a human body in floodwaters, take into account the rapid changes in the flow regime, which often occur for extreme flood events, and enable a rapid assessment of the degree of flood hazard risk in a short time period, a feature particularly important when assessing flood hazard indices for high Froude numbers flows.
\end{abstract}

Keywords Extreme floods · Large floods · Flash floods · Flood hazard · Flood risk · DIVAST-TVD

\section{Davor Kvočka}

kvockad@cf.ac.uk

1 Hydro-Environmental Research Centre, School of Engineering, Cardiff University, Cardiff CF24 3AA, UK 


\section{Introduction}

Flooding is the most frequently occurring natural disaster in the world (Jonkman 2005). However, it is expected that flooding is going to occur even more frequently in the future as a result of climate change (Lenderink and Van Meijgaard 2008; Min et al. 2011; Rojas et al. 2013; Bruwier et al. 2015). As well as the expected increase in the magnitude and frequency of future flooding, there will also be an increase in the world's population from the current level of 7.3-9.7 billion by 2050 (UN 2015). Furthermore, it is projected that $66 \%$ of the world's population will live in urban areas by 2050 (UN 2014), while in the near future $40 \%$ of the global urban land will be located in areas highly prone to flooding (Güneralp et al. 2015). In addition, $90 \%$ of the projected urban expansion is going to take place in Asia and Africa (UN 2014), e.g. in countries where millions of people already live in high-frequency flood zones (Muis et al. 2015). Therefore, the number of people affected annually by flooding will almost certainly increase significantly in the future.

As a result of climate change, there will also be an increase in the frequency and intensity of extreme rainfall events (Beniston 2009), which in turn is expected to result in more frequent occurrences of extreme flood events (Alfieri et al. 2015). Categorizing past flood events as normal or extreme can be a matter of debate. However, there are some orientation guides that can be used for categorizing the scale of past flood events. Brakenridge (2012) proposed two indices for characterizing flood events: flood severity and flood magnitude. The flood severity is not an exact descriptive statistic, but more of an orientation method that allows the use of expert judgment to estimate how unusual was the flood or discharge (Kundzewicz et al. 2013). Three flood severity classes were defined, which are based on the flood recurrence interval: Class 1 includes large flood events with a return period of the order 10-20 years, Class 2 includes very large flood events with a return period of between 20 and 100 years, and Class 3 includes extreme flood events with a return period equal to, or greater than, 100 years (Brakenridge 2012; Kundzewicz et al. 2013). Severity is an important flood characteristic, but it does not provide information on other critical aspects of flooding, such as flood duration or the extent of flooding (Kundzewicz et al. 2013). Therefore, a second statistic is needed, e.g. flood magnitude. Flood magnitude is defined as a function of flood severity, flood duration and flood inundation area (Brakenridge 2012). Flood magnitude is designed to mimic the Richter scale for earthquakes and thus provides a continuous metric, instead of just artificially classifying floods into different flood classes (Kundzewicz et al. 2013).

Determining the scale of past flood events should therefore be based on statistical descriptors (i.e. flood severity), spatiotemporal descriptors (i.e. flood magnitude) and also on socio-economical descriptors (i.e. the extent of flood damage, human casualties, psychological impact). This being the case, an extreme flood event can be simply characterized as a flood event with a small probability of occurrence, but with a significant impact on human society in terms of general damage, human casualties and overall social disruption. Taking into account all of these considerations, four types of flood events can be generally characterized as extreme flood events, including: (1) dam-break floods (Duffaut 2013; Bergman et al. 2014; Raška and Emmer 2014), (2) storm surges (Chau et al. 2013; Breilh et al. 2014; Androulidakis et al. 2015), (3) flash floods (Moussa and Bocquillon 2009; Martínez Ibarra 2012; Foulds et al. 2014; Amengual et al. 2015; Kvočka et al. 2015), and (4) extreme/large river floods (Zhi-Yong et al. 2013; Bruwier et al. 2015; Herget et al. 2015; Schröter et al. 2015; Antico et al. 2016). Among these types of extreme flood events, flash floods and large river floods are the most common and generally the most serious 
extreme events (Ashley and Ashley 2008; Di Baldassarre et al. 2010), which pose the greatest flood risk to the general population.

Flood risk assessment methods mainly consist of four steps, including: hazard assessment, exposure assessment, vulnerability assessment and risk assessment (Penning-Rowsell et al. 2005b; Foudi et al. 2015). Even though all of these steps are important in the flood risk assessment process, flood hazard assessment usually receives most attention as flood hazard maps are used for estimating the danger to people due to flooding (Koks et al. 2015). According to the Department for the Environment, Food and Rural Affairs (Defra) at the UK Environment Agency, flood hazard "describes the flood conditions in which people are likely to be swept over or drown in a flood", with these conditions being as a result of the combined effect of: (1) the depth of flow, (2) the velocity of flow, (3) the presence of debris in the flow, and (4) the spatial and temporal dynamics of these parameters (Ramsbottom et al. 2006). In other words, flood hazard assessment defines stability threshold for people in floodwaters. In floodwaters, people predominately lose stability due to two hydrodynamic or stability mechanisms: toppling or moment instability and sliding or friction instability (Jonkman and Penning-Rowsell 2008a, b; Cox et al. 2010; Xia et al. 2014).

There are two different types of criteria for assessing the human stability in floodwaters, i.e. the degree of flood hazard (Xia et al. 2011), including: (1) formulae based on mechanical analysis and calibrated using laboratory experiments with models and/or real human subjects (Foster and Cox 1973; Abt et al. 1989; Takahashi et al. 1992; Karvonen et al. 2000; Yee 2003; Jonkman and Penning-Rowsell 2008a, b; Russo et al. 2013), and (2) formulae based on empirical or quasi-theoretical studies (Keller and Mitsch 1993; Lind et al. 2004; Penning-Rowsell et al. 2005a; Ramsbottom et al. 2003, 2006; Ishigaki et al. 2005, 2009). However, flood hazard assessments methods based only on laboratory experiments with models and/or real human subjects are usually too dependent on the physical characteristics of the model or the human subject, and cognitive characteristics of the tested human subjects, whereas flood hazard assessment methods based on empirical or quasi-theoretical work often excessively over-simplify the anatomy of human body and the hydraulic characteristics of the flow (Jonkman and Penning-Rowsell 2008a, b; Xia et al. 2014). These shortcomings could particularly be relevant when it comes to designing safety criteria in areas prone to extreme flood events, since such events are generally associated with deep floodwaters, high velocity flows and the occurrences of abrupt changes in the flow regime (e.g. hydraulic jumps). Such floods require full physical representation in order to be adequately integrated in the prediction of flood hazard indices. Therefore, there is a need to improve on the current flood hazard assessment methods used, or to develop new methods, that would be based more on representing the physics accurately rather than on simple empirical relations.

The main aim of this study is to raise awareness about limitations of flood hazard assessment schemes currently in use, and in particular for areas susceptible to the occurrence of extreme flood events, such as flash flooding or large river flooding. Therefore, the key objective is to investigate and determine what type of flood hazard assessment methods should be used for assessing the hazard risk to people caused by extreme flooding. In this study, two different types of flood hazard criteria were tested, namely a classical and widely used empirically based approach, and a recently proposed physically based and experimentally calibrated approach. The two selected flood hazard assessment methods were: (1) validated against different experimental datasets, including datasets based on experiments using real humans as test subjects and datasets based on experiments using a scaled model human body, and (2) used to assess flood hazard indices for two different 
extreme flood events, including one extreme river flood event and one flash flood event. The results obtained suggest that the flood hazard assessment in areas prone to extreme flooding should be conducted with flood hazard assessment methods based on a mechanicsbased analysis, i.e. the recently introduced physically based and experimentally calibrated methods, such as the method considered in this study. These methods are highly adaptable to complex hydrodynamic processes associated with extreme flood events and are generic. The findings in this paper should be of particular interest to government departments (national and regional) and regulatory and planning authorities, as the findings presented herein should help to improve on the general flood hazard assessment data, and procedures used for emergency services and planning assessment.

\section{Study areas}

\subsection{Kostanjevica na Krki}

Kostanjevica na Krki is one of the oldest and smallest towns in Slovenia, EU. It is located in the south-eastern part of Slovenia, near the border with Croatia. The centre of the town lies on a small artificial island, surrounded by the River Krka (see Fig. 1), and is protected as a cultural town with historical monuments. Due to rich historical and cultural heritage, and frequent flooding, the town is also promoted as the "Venice of Lower Carniola".

During the period between 17th and 19th September 2010, Slovenia was hit by heavy and extensive precipitation, which led to a sharp rise in the water levels in watercourses and flooding occurred all over the country (Slovenian Environment Agency 2010a). In the territory of Slovenia, an average of 170-180 mm of rainfall fell over $48 \mathrm{~h}$ period, which was the highest amount of rainfall accumulated in two-day period over the past 60 years

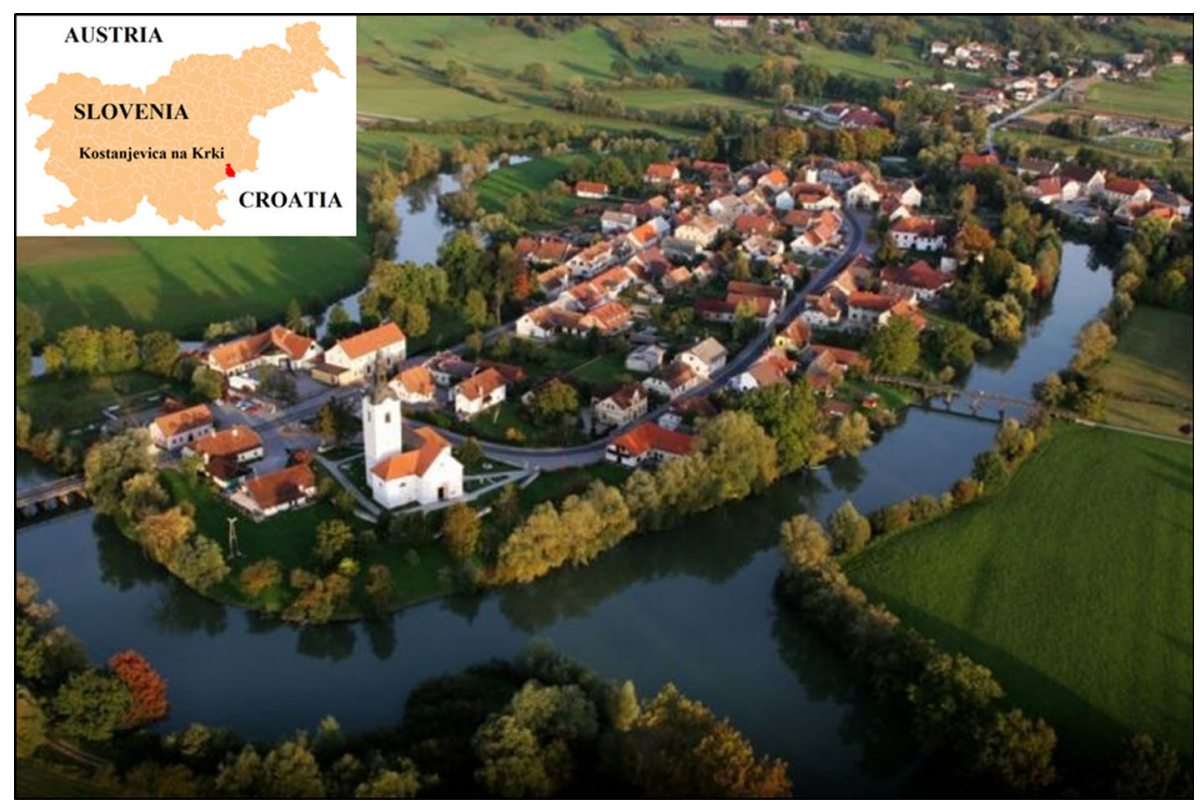

Fig. 1 Town of Kostanjevica na Krki 
(Slovenian Environment Agency 2010b). The River Krka started flooding on the evening of 18th September, and on the 19th September the town of Kostanjevica na Krki was flooded (Kobold 2011). The data from the nearby stream gage station at Podbočje revealed that the peak discharge of $468 \mathrm{~m}^{3} / \mathrm{s}$ occurred on 20th of September (Slovenian Environment Agency 2010a). This was the highest measured discharge for the River Krka since the beginning of measurements in 1926 and statistically corresponds to nearly a 1 in 1000 year flood event (Kobold 2011; Slovenian Environment Agency 2013).

Topographic data for the Kostanjevica na Krki study domain were collected during a national project of LiDAR (Light Detection and Ranging) scanning of the Slovenian surface (Ministry of the Environment and Spatial Planning of the Republic of Slovenia 2015). These LiDAR data were then used to set up a hydraulic model for the 2010 Kostanjevica na Krki extreme river flood event. The study domain (see Fig. 2) was $705 \mathrm{~m}$ long, $641 \mathrm{~m}$ wide and divided into square cells, with each cell having an area of $1 \mathrm{~m}^{2}$. The western boundary of the domain was set as an inflow boundary for the River Krka, with the peak discharge being specified as the upstream boundary condition. The area where the River Krka leaves the study domain was set as the downstream boundary, with a prescribed water level being specified as the downstream boundary condition.

Three wooden bridges connect the old town centre with the surrounding area, namely the North Bridge, the South Bridge and the Tercijalski Bridge. There were no official reports or eye-witness accounts suggesting that any of the three bridges were blocked during the time of the flood event. This being the case, there was no need to specifically model bridges in the hydraulic model for the Kostanjevica na Krki study domain.

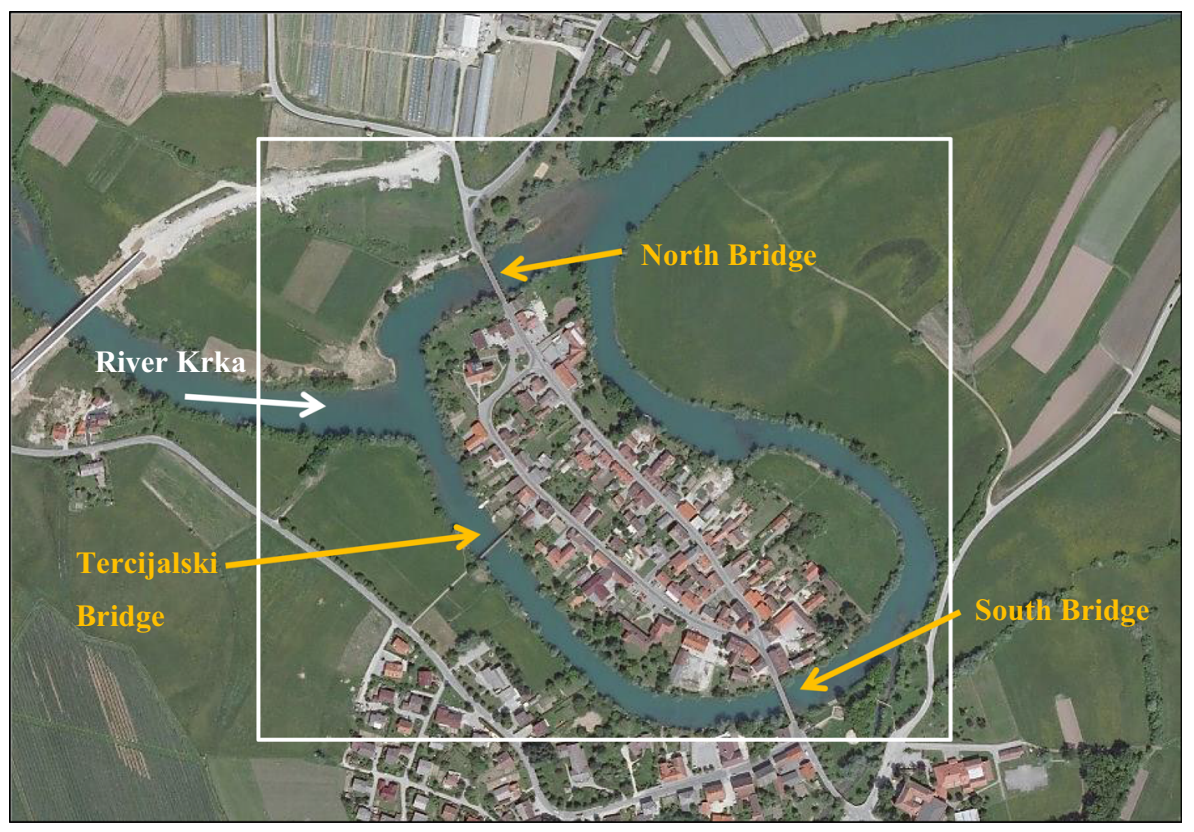

Fig. 2 Kostanjevica na Krki study domain 


\section{2 Železniki}

Železniki is a small town in the north-west part of Slovenia, EU. The town is situated in the long and narrow Selca Valley, which stretches along the River Selška Sora. The Selca Valley, and in particular the Selška Sora catchment area upstream of Železniki, is characterized by a steep topographic terrain and relatively thin soils on the hillslopes (Zanon et al. 2010). The town of Železniki is the administrative centre and the largest settlement in the Selca Valley. Železniki is also the economic hub of the area, with relatively large metalworking and furniture factories being based in the town (see Fig. 3).

On the 18th of September 2007, there was a region of low air pressure over Northern Europe, which was moving over western and middle Europe towards the Alps. In addition to a low-pressure weather system, a high valley of cold air was moving over Western Europe towards the east, while the south-western wind was getting stronger and stronger over Slovenia. As a result of these complex weather conditions, an extensive convective system formed over the north-western part of Slovenia, which led to the occurrence of an extreme rainfall event that affected approximately one-third of the country (Slovenian Environment Agency 2008). More than $300 \mathrm{~mm}$ of rainfall was recorded on some raingauge stations within six hours after the start of the storm, with the return period of the highest precipitation being more than 100 years (Kobold et al. 2008). In Železniki, the observed maximum daily amount of rainfall was nearly $200 \mathrm{~mm}$, which was the highest recorded amount of rainfall since the beginning of the measurements in 1930 (Grillakis et al. 2010). The accumulated rainfall resulted in a flood event that by far exceeded the 100 -year return period of maximal floods, with the estimated peak discharge being around

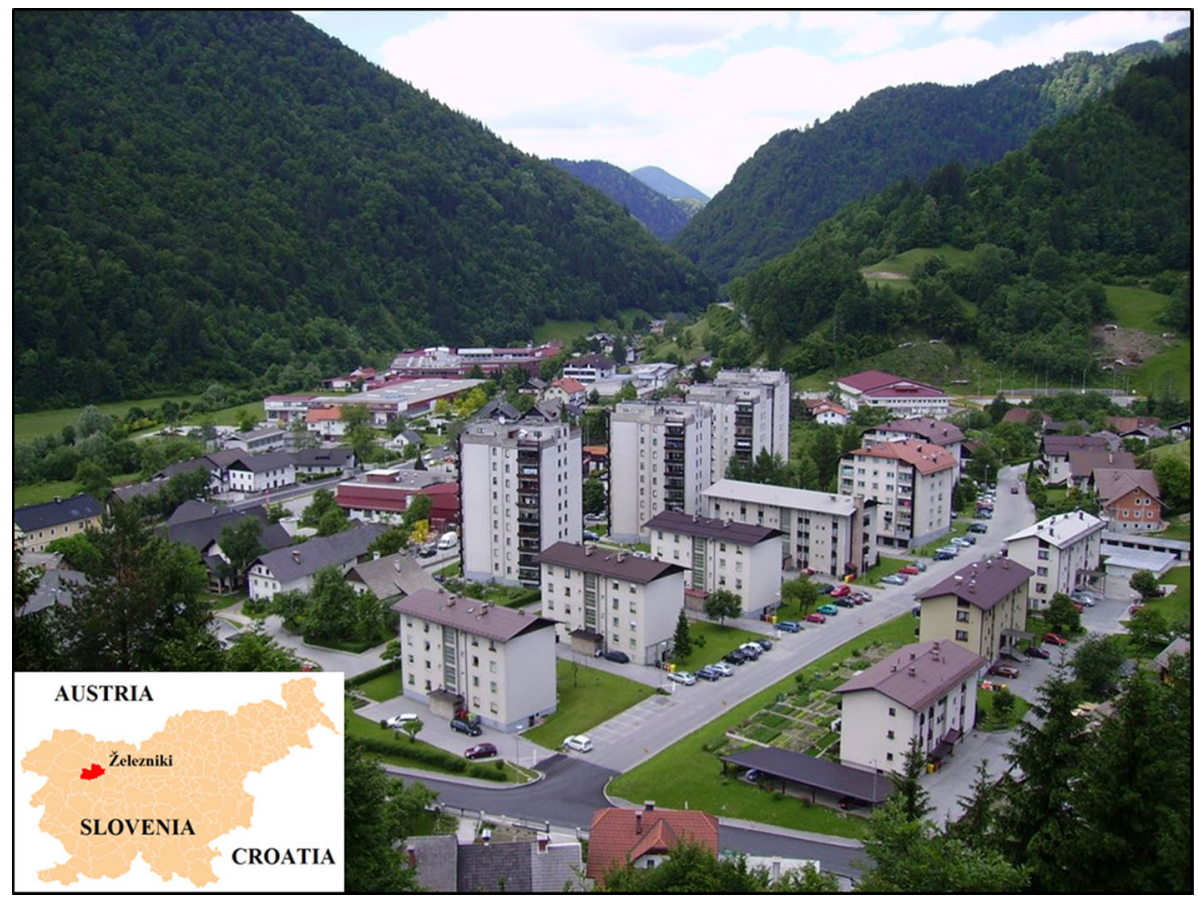

Fig. 3 Town of Železniki 
$300 \mathrm{~m}^{3} / \mathrm{s}$ (Rusjan et al. 2009; Marchi et al. 2009; Zanon et al. 2010). The flash flood triggered by the intense precipitation devastated the town of Železniki: three people lost their lives, while it was estimated that the flood caused nearly 100 million Euros of damage (Bouilloud et al. 2009).

Topographic data for the Železniki study domain were collected during the national project of LiDAR scanning of the Slovenian surface (Ministry of the Environment and Spatial Planning of the Republic of Slovenia 2015). These LiDAR data were then used to set up a hydraulic model for the 2007 Železniki flash flood event. The study domain (see Fig. 4) was $1966 \mathrm{~m}$ long, $1285 \mathrm{~m}$ wide and divided into square cells, with each cell having an area of $1 \mathrm{~m}^{2}$. The western boundary of the domain was set as an inflow boundary for the River Selška Sora, with the peak discharge being specified as the upstream boundary condition. The eastern boundary of the study domain was set as the downstream boundary, with a prescribed water level being specified as the downstream boundary condition.

\section{Numerical model}

The research presented in this paper was conducted using the DIVAST-TVD numerical model. The DIVAST-TVD model is a shock-capturing flood simulation model, which was developed by Liang et al. (2007a). The DIVAST-TVD model was specifically developed to simulate the hydrodynamic processes in rivers and coastal waters by solving the shallow water equations, with the model being predominately used for simulating rapidly varying flood events and high Froude number flows (Liang et al. 2007b, 2014; Kvočka et al. 2015).

This numerical model combines the standard MacCormack scheme with a symmetric five-point total variation diminishing (TVD) term. The MacCormack scheme is a

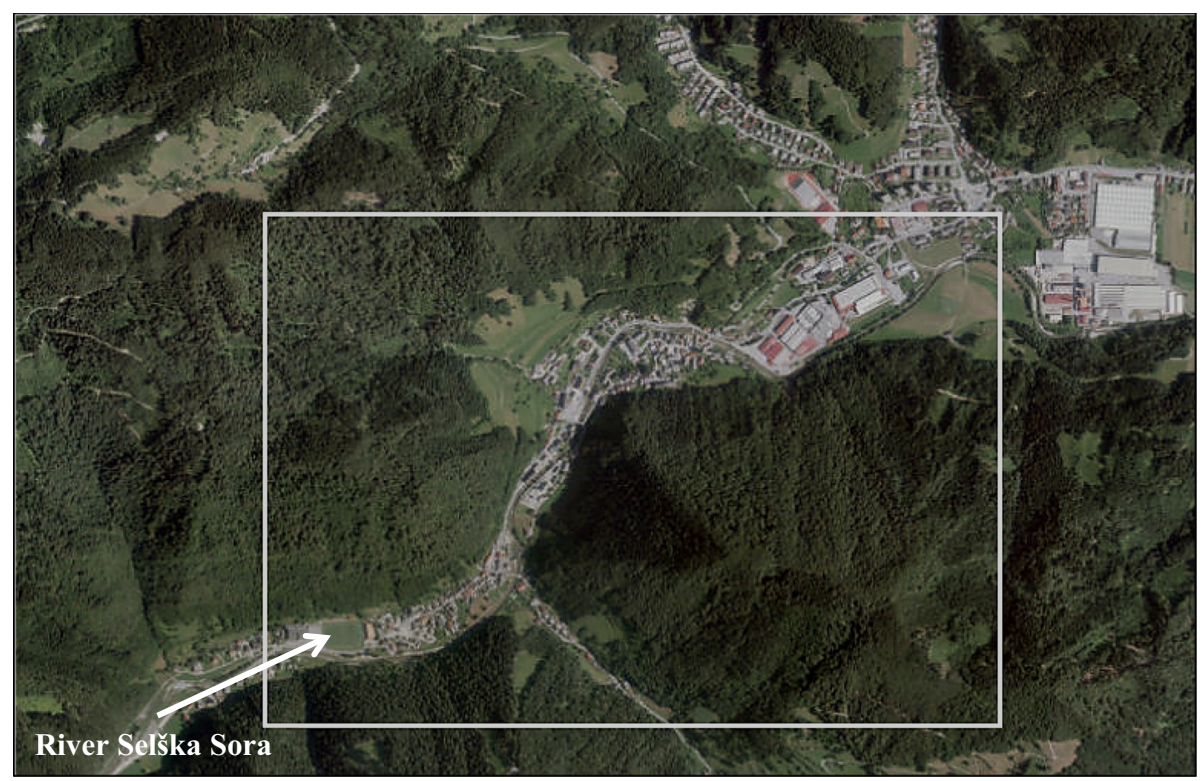

Fig. 4 Železniki study domain 
numerical method ideally suited for solving the time-dependent compressible NavierStokes equations (MacCormack 1976). The MacCormack scheme is a predictor-corrector scheme and is a variation of the Lax-Wendroff scheme (Lax and Wendroff 1960). In the MacCormack scheme, the predictor step calculates a rough approximation of the desired variable, whereas the corrector step refines the initial approximation. The standard MacCormack scheme has second-ordered accuracy (MacCormack 1976). It is well known that all schemes of accuracy greater than one will generate spurious numerical oscillations in the regions where the gradient is high (Godunov 1959). Therefore, a symmetric fivepoint TVD term is appended to the corrector step of the MacCormack scheme to prevent non-physical oscillations. Total variation diminishing schemes prevent the emergence of numerical oscillations through added nonlinear artificial dissipation terms (Mingham et al. 2001). The concept of TVD was first introduced by Harten (1983), whereas the TVD term implemented in the DIVAST-TVD model was first presented by Davis (1984). Davis (1984) proposed a total variation diminishing scheme where a symmetric five-point TVD term is added to the Lax-Wendroff scheme. The symmetric five-point TVD term is used to adjust the introduced numerical diffusion: a second-order accurate MacCormack scheme is deployed where the solution is smooth, whereas a first-order accurate upwind scheme is deployed to avoid spurious numerical oscillations (Liang et al. 2007a).

The DIVAST-TVD model is an effective tool for analysing storm surges, dam-break scenarios, flash floods, etc., i.e. any flow scenario that could involve rapid changes in the flow regime. The information about model development and extensive model verifications can be found in the literature (Liang et al. 2006, 2007b; Hunter et al. 2008; Neelz and Pender 2009; Liang et al. 2010; Kvočka et al. 2015).

\section{Flood hazard assessment methods}

Two different flood hazard assessment methodologies were considered in this paper: (1) an empirically derived method (Ramsbottom et al. 2003, 2006), and (2) a physically based and experimentally calibrated method (Xia et al. 2014).

\subsection{Empirically derived method}

Ramsbottom et al. (2003) developed a methodology for assessing and mapping the risk to people caused by flooding, with this methodology being developed for the Department for the Environment, Food and Rural Affairs (DEFRA) and the UK Environment Agency. Based on testing various empirical formulae by comparing the predictions to experimental datasets obtained from laboratory and field-based studies conducted by Abt et al. (1989), Karvonen et al. (2000), (Cox et al. 2010) and Ramsbottom et al. (2003) proposed an empirical formula, which assesses the flood hazard to people as follows:

$$
\mathrm{HR}=d(v+1.5)+\mathrm{DF}
$$

where HR is the flood hazard rating $\left(\mathrm{m}^{2} / \mathrm{s}\right), \mathrm{d}$ is the water depth $(\mathrm{m}), v$ is the velocity of the flow $(\mathrm{m} / \mathrm{s})$ and DF is the debris factor $\left(\mathrm{m}^{2} / \mathrm{s}\right)$, which can have a value of 0,1 or 2 , depending on the place of the flood and on the features of the flow.

In the review of the original study, Ramsbottom et al. (2006) revised the initially proposed formula, i.e. Eq. (1), wherein: the velocity coefficient was reduced from 1.5 to 
0.5 , while the values for the debris factor were reduced from the initial values of 0,1 and 2 to values of $0,0.5$ and 1 . This being the case, the revised formula is given as:

$$
\mathrm{HR}=d(v+0.5)+\mathrm{DF}
$$

where HR is the flood hazard rating $\left(\mathrm{m}^{2} / \mathrm{s}\right), \mathrm{d}$ is the water depth $(\mathrm{m}), \mathrm{v}$ is the velocity of the flow $(\mathrm{m} / \mathrm{s})$ and $\mathrm{DF}$ is the debris factor $\left(\mathrm{m}^{2} / \mathrm{s}\right)$.

Based on the revised formula, i.e. Eq. (2), Ramsbottom et al. (2006) proposed various flood hazard classifications, which are given in Table 1.

The empirical expression, i.e. Eq. (2), presented by Ramsbottom et al. (2006) has some shortcomings, including (Cox et al. 2010): (1) the flow regime values from the experimental datasets were averaged, and thus some training (e.g. the ability of the test subject to learn how to manoeuvre in the flow with time) was incorporated in the derived expression; however, this is usually not the case with the general population, as majority of people do not have the experience of standing or manoeuvring in floodwaters, (2) the assigned values for the debris factor were not based on, or supported by, any experimental testing, and (3) the proposed expression has no upper depth limit, and therefore large depth/low velocity flood flows are not necessarily considered as hazardous, i.e. the flow conditions in which a person would be floating, and thus completely dependent upon swimming ability, are not automatically classed as dangerous. Nevertheless, flood hazard maps issued by the regulatory authorities in the UK (e.g. DEFRA) are based on the flood hazard assessment method presented by Ramsbottom et al. (2006). Furthermore, the criterion presented herein is also well established outside the UK (Penning-Rowsell et al. 2005a; Kaźmierczak and Cavan 2011; Purwandari et al. 2011; Foudi et al. 2015). This being the case, the formula presented by Ramsbottom et al. (2006) is generally considered as an accurate criterion for assessing and mapping hazard to people due to flooding.

\subsection{Physically based and experimentally calibrated method}

Xia et al. (2014) derived a new method for assessing human stability in floodwaters, which is based on extensive theoretical and experimental studies. The formulae proposed by Xia et al. (2014) are based on the mechanisms of toppling and sliding instability, and were derived by considering all forces acting on a human body in floodwater, e.g. drag force, frictional force, gravitational force, buoyancy force and normal reaction force. Furthermore, the new formulae also (1) take into account the effect of a non-uniform upstream velocity profile on the stability of a person standing in a floodwater, and (2) consider the impact of the body buoyancy for rapidly varying water depths (Xia et al. 2014).

Two formulae were proposed. Firstly, the incipient velocity is given for a human body in floodwater experiencing sliding instability:

Table 1 Flood hazard to people (Ramsbottom et al. 2006)

\begin{tabular}{lll}
\hline HR & Degree of flood hazard & Description \\
\hline$<0.75$ & Low & Caution \\
$0.75-1.5$ & Moderate & Dangerous for some (i.e. children) \\
$1.5-2.5$ & Significant & Dangerous for most people \\
$>2.5$ & Extreme & Dangerous for all \\
\hline
\end{tabular}




$$
U_{c}=\alpha\left(\frac{h_{f}}{h_{\mathrm{p}}}\right)^{\beta} \sqrt{\frac{m_{\mathrm{p}}}{\rho_{f} h_{\mathrm{p}} h_{f}}-\left(a_{1} \frac{h_{f}}{h_{\mathrm{p}}}+b_{1}\right) \frac{\left(a_{2} m_{\mathrm{p}}+b_{2}\right)}{h_{\mathrm{p}}^{2}}}
$$

where $U_{c}$ is the incipient velocity, $h_{f}$ is the water depth $(\mathrm{m}), h_{\mathrm{p}}$ is the height of a person $(\mathrm{m})$, $m_{\mathrm{p}}$ is the weight of a person $(\mathrm{kg}), \rho_{f}$ is the density of water $\left(\mathrm{kg} / \mathrm{m}^{3}\right), \alpha$ and $\beta$ are empirical coefficients and $a_{1}, a_{2}, b_{1}$ and $b_{2}$ are coefficients based on the characteristics of a human body.

Secondly, the incipient velocity for a human body in floodwater experiencing toppling instability is given as:

$$
U_{c}=\alpha\left(\frac{h_{f}}{h_{\mathrm{p}}}\right)^{\beta} \sqrt{\frac{m_{\mathrm{p}}}{\rho_{f} h_{f}^{2}}-\left(\frac{a_{1}}{h_{\mathrm{p}}^{2}}+\frac{b_{1}}{h_{f} h_{\mathrm{p}}}\right)\left(a_{2} m_{\mathrm{p}}+b_{2}\right)}
$$

where $U_{c}$ is the incipient velocity, $h_{f}$ is the water depth $(\mathrm{m}), h_{\mathrm{p}}$ is the height of a person $(\mathrm{m})$, $m_{\mathrm{p}}$ is the weight of a person $(\mathrm{kg}), \rho_{f}$ is the density of water $\left(\mathrm{kg} / \mathrm{m}^{3}\right), \alpha$ and $\beta$ are empirical coefficients and $a_{1}, a_{2}, b_{1}$ and $b_{2}$ are coefficients based on the characteristics of a human body.

Finally, the degree of flood hazard for each instability mechanism can be quantified with the following expression:

$$
\mathrm{HR}=\operatorname{MIN}\left(1, \frac{U}{U_{c}}\right)
$$

where HR is the flood hazard rating, $U$ is the velocity of the flow and $U_{c}$ is the incipient velocity, e.g. the velocity at which person loses stability in floodwater.

The main difference between the majority of empirically derived flood hazard formulae and this physically based and experimentally calibrated method is in the way they take into account forces induced by flow conditions. In Eqs. (3) and (4), it can be seen that the overturning force on the body is proportional to the water depth times the velocity squared (i.e. $h v^{2}$ ), whereas for the empirically derived formula [see Eq. (2)] the overturning force on the body is proportional to the water depth times velocity only (i.e. hv). This means that the physically based and experimentally calibrated method can be much more influenced by higher velocities and momentum, with such conditions frequently occurring with extreme flood events. This being the case, this physically based and experimentally calibrated method is highly adaptable to abrupt changes in the flow regime and can rapidly and more accurately assess the degree of flood hazard risk in a short time period, characteristic particularly important for flood hazard assessment of extreme flood events.

A further advantage of the physically based and experimentally calibrated methods is that they can be adjusted to a specific body type (Xia et al. 2014; Milanesi et al. 2015). For example, by applying a biomechanical model, such as the $3 \mathrm{D}$ biomechanical model presented by Nikolova and Toshev (2007), Eqs. (3) and (4) can assess the stability of people according to their height, weight and body parameter characteristics, e.g. length, mass and the corresponding volume of a particular body part, such as legs, torso, arms. This means that stability thresholds can be defined specifically for: (1) different sub-population groups of the general population, such as males, females and children, and (2) that stability thresholds can be defined explicitly for different geographic regions or countries, such as Europe, America or the Far East. 


\section{Methodology}

The initial assumption of this study was that the physically based and experimentally calibrated method would more accurately assess the flood hazard indices for people than the empirically derived method when the flood hazard is assessed for extreme flood events. In order to test this assumption, two different validation procedures were undertaken.

Firstly, both flood hazard assessment criteria were validated against two different types of experimental data, i.e. the data based on the experiments including real human test subjects and the data based on the experiments using model human bodies. The experiments, including real human test subjects, conducted by Abt et al. (1989) and Karvonen et al. (2000), were considered herein. There are several other studies where real humans as test subjects have been used, such as the studies conducted by Foster and Cox (1973), Takahashi et al. (1992) and Jonkman and Penning-Rowsell (2008a, b). However, the focus in this study is on the experimental data by Abt et al. (1989) and Karvonen et al. (2000), as these two datasets were included in the derivation process of the empirically based method considered herein and have the largest amount of experimental observations among the available experimental datasets. It should be noted that Russo et al. (2013) have collected the largest amount of experimental observations to date (more than 800 tests were performed in this study). Unfortunately, this dataset was not available and thus was not considered in this study.

In the experiments conducted by Abt et al. (1989) and Karvonen et al. (2000), the water depth and the corresponding velocity were recorded when the human test subject lost manoeuvrability or stability in the flume due to the flow conditions. The authors of these two studies did not specifically record which instability mechanism led to the loss of stability of the test subject during a particular test. Nonetheless, it can be established from the recorded data that only in a few tests the stability was lost due to sliding, whereas in the vast majority of the tests the stability was lost due to toppling (Jonkman and PenningRowsell 2008a, b; Xia et al. 2014). In contrast to experiments with real human test subjects, Xia et al. (2014) used a scaled human body (i.e. a dummy) for their experiments. The scaled human body strictly followed the principles of geometric, kinematic and dynamic scaling, which meant that the flow conditions were ideally similar to those in the prototype (Chanson 2004), e.g. density, drag and friction coefficient of the selected human body model were approximately equal to those of the prototype (Xia et al. 2014). This being the case, the prototype, at $1.70 \mathrm{~m}$ in height and $60 \mathrm{~kg}$ in weight, was scaled down to a model human body of $0.3 \mathrm{~m}$ in height and $0.334 \mathrm{~kg}$ in weight, with the model human body strictly following the geometric similarity in each dimension. For each test, the water depth and the corresponding velocity were recorded at the moment when the model human body started to become unstable. In addition, the instability mechanism (e.g. toppling or sliding), which led to instability of the model human body, was identified for each test.

As mentioned previously, the physically based and experimentally calibrated method considered herein can be adjusted to a specific body type. The characteristics of a specific body type in Eqs. (3) and (4) are represented with coefficients $a_{1}, b_{1}, a_{2}$ and $b_{2}$. More precisely, the coefficients $a_{1}, b_{1}, a_{2}$ and $b_{2}$ form part of an expression, which represents the effect of the buoyancy force as a function of the human height and mass for a given water depth (Xia et al. 2014). These coefficients can be determined from the characteristics of the human body, e.g. the human height and mass, and the volume and mass of the body segment parameters, such as legs, arms, torso. For example, based on the body segment characteristics of a typical Bulgarian body (Nikolova and Toshev 2007), the values of $a_{1}$ 
and $b_{1}$ were assumed to be 0.612 and 0.388 , while according to the body structure of an American body (Drillis et al. 1964), the value of the coefficients $a_{1}$ and $b_{1}$ was 0.737 and 0.263 , respectively (Xia et al. 2014). For the coefficients $a_{2}$ and $b_{2}$, these can be obtained from the relationship between the total body volume and the corresponding mass of a human body. Hence, the values of the coefficients $a_{2}$ and $b_{2}$ for a typical Bulgarian body, for example, were assumed to be $0.9748 \times 10^{-3} \mathrm{~m}^{3} / \mathrm{kg}$ and $-0.7111 \times 10^{-3} \mathrm{~m}^{3}$. In addition, the coefficients $a_{1}, b_{1}, a_{2}$ and $b_{2}$ are constant, which means that the same values of these coefficients apply for both instability mechanisms, as given by Eqs. (3) and (4). The value of the coefficients $a_{1}, b_{1}, a_{2}$ and $b_{2}$ for the model human body used in this study was: $a_{1}=0.633, b_{1}=0.367, a_{2}=1.015 \times 10^{-3} \mathrm{~m}^{3} / \mathrm{kg}$ and $\mathrm{b}_{2}=-4.927 \times 10^{-3} \mathrm{~m}^{3}$ (Xia et al. 2014).

Two parameters are needed to calibrate the physically based and experimentally calibrated method considered herein, i.e. parameters $\alpha$ and $\beta$ [see Eqs. (3) and (4)]. These two parameters can be evaluated from the relevant experimental data and are influenced by the shape of the test subject, the friction coefficient between the soles and the ground surface, the drag coefficient, the effect of a non-uniform velocity distribution along the vertical direction, and the effect of the ability of a test subject to adjust its position in the flow (Xia et al. 2014). Hence, the values of the parameters $\alpha$ and $\beta$ are different for each body type and for each instability mechanism. However, as the height, mass and the values of the aforementioned coefficients are constant for a particular human body, the values of parameters $\alpha$ and $\beta$ can be evaluated by statistical analysis from the relevant experimental data (Xia et al. 2014). As we were modelling sites in Slovenia, it would be reasonable to calibrate Eqs. (3) and (4) for the body characteristics of people living in these two countries. Unfortunately, such calibrations are not possible at present due to the lack of body segment parameter data needed to undertake the calibration process. Alternatively, Eqs. (3) and (4) could be calibrated for a typical Bulgarian body, since the necessary body segment parameter data exists (Nikolova and Toshev 2007). These data can be used to represent a model human body based on the typical Bulgarian body prototype, with the model human body being used for the experimental tests and thus for calibration of Eqs. (3) and (4). However, as the difference in size and body characteristics between a typical Bulgarian body and the body considered in the study of Xia et al. (2014) is relatively small, it was decided to use the values of the parameters $\alpha$ and $\beta$ obtained in the study by Xia et al. (2014) for the calibration of Eqs. (3) and (4) in this study. This saved valuable resources and time that would otherwise be spent on experimental procedures, yet still enabled satisfactory quality of the final results as the potential computational error is in an acceptable range. The values of the parameters $\alpha$ and $\beta$ used in this study for the calibration of Eqs. (3) and (4), for both the model human body considered by Xia et al. (2014) and the real human body (i.e. data collected in the experiments considering real human test subjects), are presented in Table 2.

Table 2 Values of the parameters $\alpha$ and $\beta$ used to calibrate the physically based and experimentally calibrated method for the model human body and real human body (Xia et al. 2014)

\begin{tabular}{llllll}
\hline \multirow{2}{*}{ Parameter } & \multicolumn{2}{l}{ Model human body } & & \multicolumn{2}{l}{ Real human body } \\
\cline { 2 - 3 } & Toppling instability & Sliding instability & & Toppling instability & Sliding instability \\
\hline$\alpha$ & 3.472 & 7.975 & 7.867 & 10.253 \\
$\beta$ & 0.188 & 0.018 & 0.462 & 0.139 \\
\hline
\end{tabular}


Secondly, the assessed flood hazard indices from both methods were compared at different stages of three extreme flood events, including one extreme river flood event and two flash flood events. In order to focus solely on the hydrodynamic conditions of the flow that can lead to loss of stability in floodwaters, any external factors that present a risk to people in floodwaters (such as floating debris) were omitted from the flood hazard assessment process. As mentioned, the physically based and experimentally calibrated method considered in this study can assess the hazard to people by considering both the sliding and toppling instability mechanisms. This being the case, the limiting stability threshold for the physically based and experimentally calibrated method was defined as the minimum of the toppling and sliding incipient velocities:

$$
\mathrm{HR}=\operatorname{MIN}\left(1, \frac{U}{\operatorname{MIN}\left(U_{\text {toppling }}, U_{\text {sliding }}\right)}\right)
$$

where HR is the flood hazard rating, $U$ is the velocity of the flow, $U_{\text {toppling }}$ is the toppling incipient velocity and $U_{\text {sliding }}$ is the sliding incipient velocity.

The empirically derived method categorizes flood hazard into four flood hazard classifications, namely: low, moderate, significant and extreme. On the other hand, the physically based and experimentally calibrated method considered herein quantifies flood hazard by mimicking the principle of bivalence, i.e. there is only one threshold that defines whether the stability of a person in floodwater is lost or not. This means that there is only one flood hazard class, i.e. extreme. However, in order to allow a more detailed comparison to be undertaken between the two flood hazard assessment methods, the assessed degree of flood hazard according to the physically based and experimentally calibrated method was divided into three additional flood hazard classifications that correspond to the flood hazard classifications of the empirically derived method, i.e. low, moderate and significant. The subdivision of the quantifying flood hazard criteria of the physically based and experimentally calibrated method, which ranges between 0 and 1 , was undertaken in such a manner that the ratio of the threshold values that separate the subdivided flood hazard classes was identical to the ratio of the threshold values that separate the flood hazard classes of the empirically based method. Therefore, if the threshold values in the empirical method are $0.75,1.5$ and 2.5 , then the corresponding values for the physically based and experimentally calibrated method would be $0.3,0.6$ and 1 . The subdivision of the physically based and experimentally calibrated method into three additional flood hazard classifications, corresponding to the flood hazard classifications of the empirically derived method, should enable better evaluation of how the two flood hazard assessment methods adapt to the violent nature of extreme flood events and thus provide more meaningful results.

In this study, extreme flood events were simulated with rapid changes occurring in the flow regime and the Froude numbers being relatively high. Therefore, there was a need to determine what type of flood simulation model should be used for predicting the main flood parameters (i.e. flood depths and velocities), which were needed for an accurate flood hazard assessment process. The shock-capturing flood simulation DIVAST-TVD model was used for predicting the main flood parameters for flash flood scenario, as only shockcapturing flood simulation model produces numerically accurate predictions of flood depths and velocities when simulating flash flood events (Kvočka et al. 2015). In order to be consistent, the DIVAST-TVD model was also used for predicting the main parameters in the extreme river flood scenario. 


\section{Results and discussion}

\subsection{Comparison with the experimental datasets}

Figure 5 shows a comparison of the flood hazard prediction ability of the two methods with the experimental observations of Abt et al. (1989), while Fig. 6 shows a comparison of the flood hazard prediction ability of the two methods with the experimental observations of Karvonen et al. (2000). As mentioned, in the experiments conducted by Abt et al. (1989) and Karvonen et al. (2000), the dominant mode of instability was due to the toppling instability mechanism (Jonkman and Penning-Rowsell 2008a, b; Xia et al. 2014), and therefore Eq. (4) was used for the comparisons with the empirically derived method. Table 3 shows the values of the parameters $\alpha$ and $\beta$ used for the calibration of Eq. (4) when the two datasets are considered separately.

In both Figs. 5 and 8, the blue circles represent the depth and velocity when stability was lost, i.e. the flow conditions which led to instability of the test subject. In Fig. 5, it can be seen that the empirically derived method classified all experimental observations into two flood hazard classes, i.e. moderate hazard and significant hazard. The majority of the experimental observations (i.e. the point in the experiments when the real human test subject was losing, or completely lost, stability) were classified as significant hazard, which indicated that the empirical method generally accurately assessed the flood hazard indices. Figure 5 also shows that the physically based and experimentally calibrated method agreed well with the experimental observations, as 38 out of 58 experimental observations can be found above the stability threshold (red line), which indicated that stability was lost, and with at least 15 experimental observations being in the relative proximity of the stability

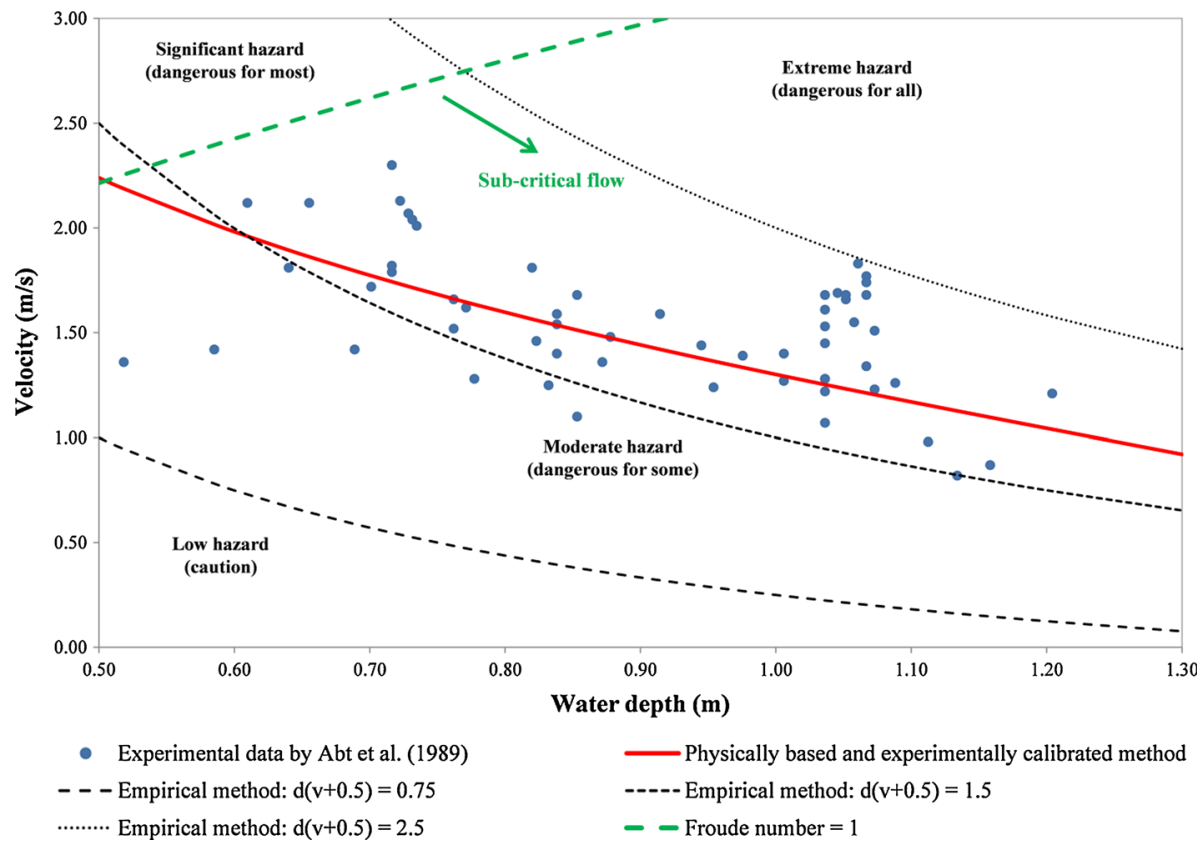

Fig. 5 Comparison of the flood hazard prediction ability of the two methods with the experimental observations of Abt et al. (1989) 


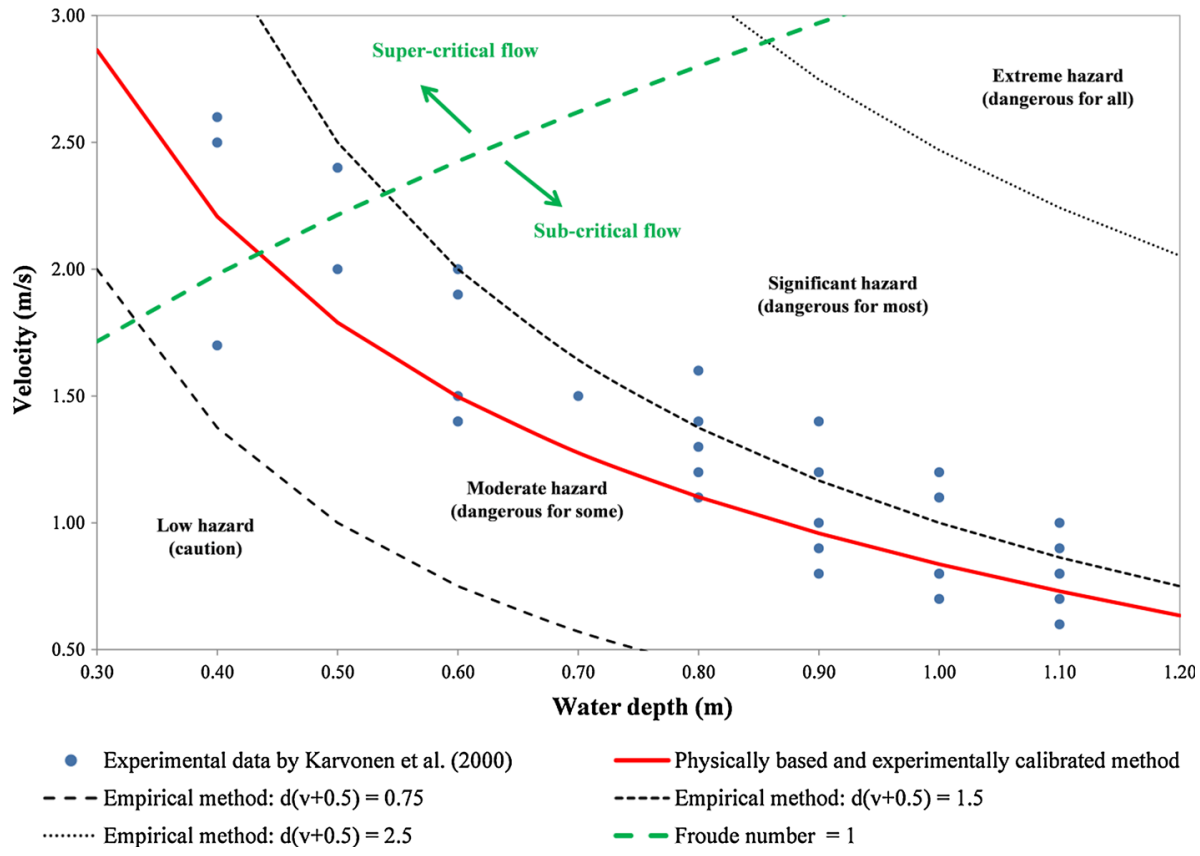

Fig. 6 Comparison of the flood hazard prediction ability of the two methods with the experimental observations of Karvonen et al. (2000)

Table 3 Values of the parameters $\alpha$ and $\beta$ used to calibrate Eq. (4) separately for each of the two datasets (Xia et al. 2014)

\begin{tabular}{lll}
\hline Parameter & $\begin{array}{l}\text { Data by Abt et al. (1989) } \\
\text { Equation (4) }\end{array}$ & $\begin{array}{l}\text { Data by Karvonen et al. (2000) } \\
\text { Equation (4) }\end{array}$ \\
\hline$\alpha$ & 8.855 & 4.825 \\
$\beta$ & 0.473 & 0.160 \\
\hline
\end{tabular}

threshold, which indicated that subject was close to losing stability, i.e. was greatly endangered by the flow conditions. In Fig. 6, it can be seen that the empirically derived method classified the majority of the experimental observations in the moderate flood hazard class, which was regarded as the stability threshold for children. This indicated that the empirically derived method underestimated the flood hazard indices for the dataset of Karvonen et al. (2000). On the other hand, Fig. 6 also shows that the physically based and experimentally calibrated method agreed, almost for all of the experimental observations, as 21 out of 29 of the experimental observations fall above the stability threshold (red line), which indicated that stability was lost. In addition, Figs. 5 and 6 also show that in practically all test runs the stability of the real human test subjects was lost in the sub-critical flow regime. Therefore, it is hard to evaluate the prediction ability of the empirically derived method for high Froude number flows, which often occur with extreme flood events. Nonetheless, it can be seen from Figs. 5 and 6 that the physically based and the experimentally calibrated method performed better than the empirically derived method. 
In contrast, the results are somewhat different when both datasets are merged. For example, Fig. 7 shows a comparison of the flood hazard prediction ability of the two methods, with the experimental data from both aforementioned experimental studies. The blue circles and orange squares represent the depth and velocity when stability was lost, i.e. the flow conditions which led to instability of the test subject. In Fig. 7, it can be seen that the empirically derived method classified all data into two flood hazard classes, i.e. moderate hazard and significant hazard. This means that nothing changed from the perspective of the empirically derived method when compared to the results presented in Figs. 5 and 8. On the other hand, Fig. 7 also shows that there was some change in the predictive ability of the physically based method. It can be seen in Fig. 7 that the physically based and experimentally calibrated method classified 57 out of 87 experimental observations as extreme hazard. However, there are now 48 experimental observations (compared to 38 in Fig. 5) from the dataset by Abt et al. (1989), and only nine experimental observations (compared to 20 in Fig. 6) from the dataset by Karvonen et al. (2000) above the stability threshold (red line) of the physically based and experimentally calibrated method.

The results in Fig. 7 show that the predictive ability of the physically based and experimentally calibrated method is closely related to the body characteristics of the test subjects, which agrees with the observations of other authors (Xia et al. 2014; Milanesi et al. 2015). As the two datasets were combined, the body characteristics (and thus the effect of buoyancy) of an average test subject changed, which consequently changed the values of the calibrating parameters $\alpha$ and $\beta$ (see Table 2), and thus stability threshold of the physically based and experimentally calibrated method. For example, average height and weight in the study of Abt et al. (1989) were $178 \mathrm{~cm}$ and $76 \mathrm{~kg}$, while for a test subject

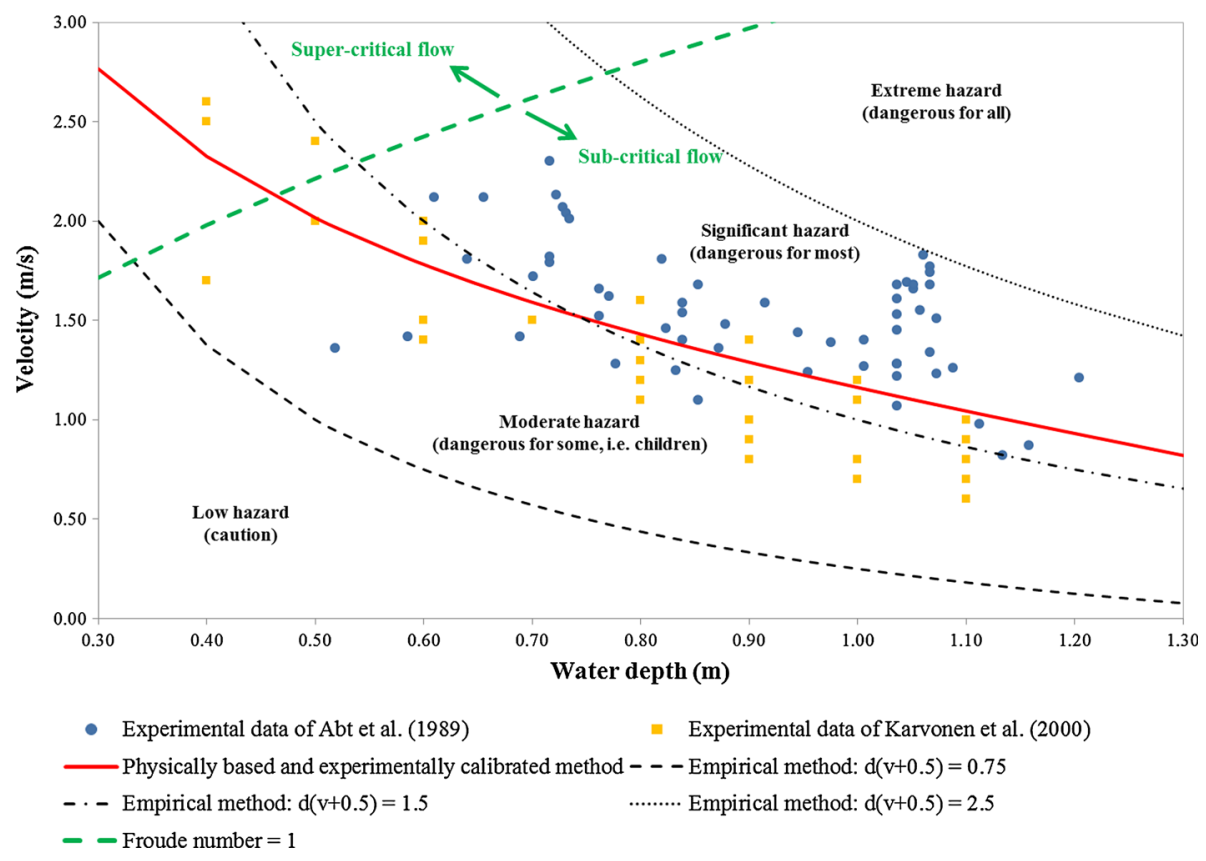

Fig. 7 Comparison of the flood hazard prediction ability of the two methods with the experimental observations of Abt et al. (1989) and Karvonen et al. (2000) 


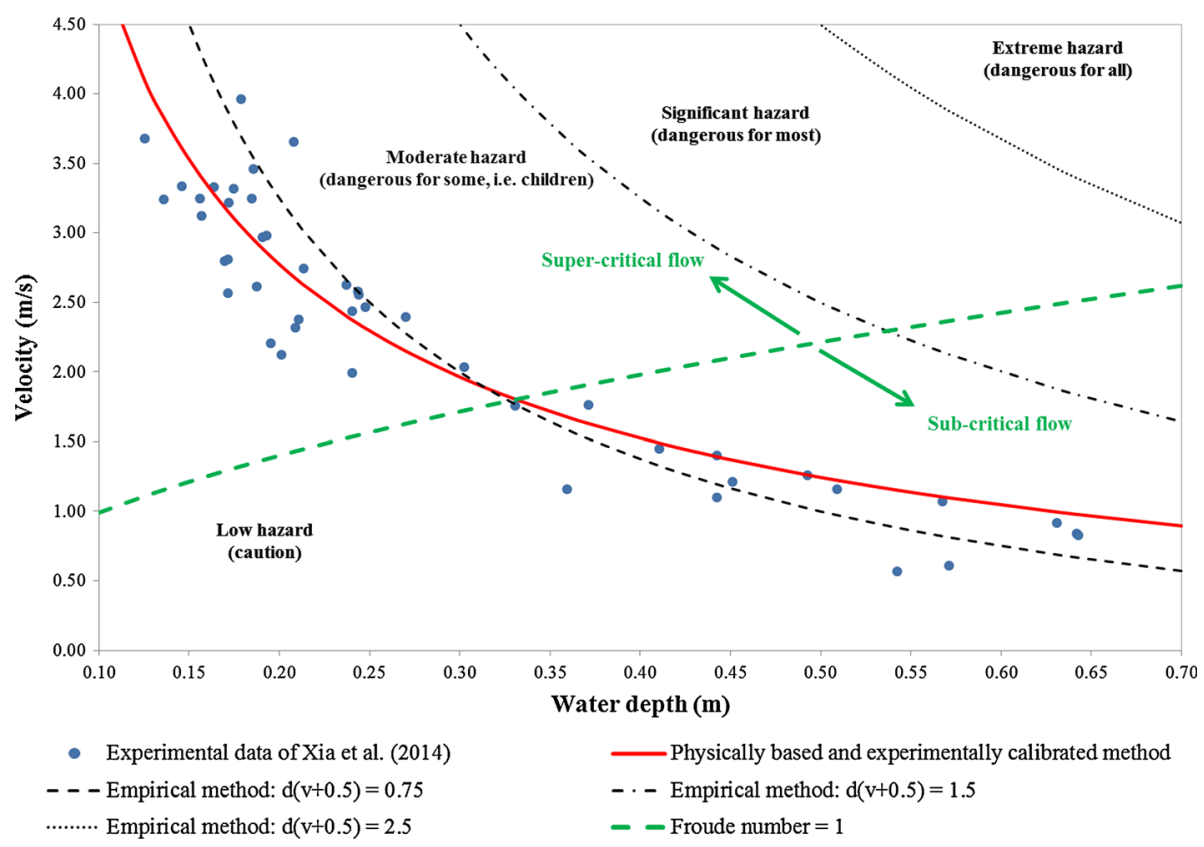

Fig. 8 Comparison of the flood hazard prediction ability of the two methods with the experimental observations of Xia et al. (2014)

in the study of Karvonen et al. (2000) they were $174.6 \mathrm{~cm}$ and $73.6 \mathrm{~kg}$, respectively. However, when both datasets are merged the average test subject is $177.1 \mathrm{~cm}$ in height and weighs $75.3 \mathrm{~kg}$, which explains why there are more experimental observations of Abt et al. (1989) above the stability threshold (red line) of the physically based and experimentally calibrated method when compared to Fig. 5, and why there are less experimental observations for Karvonen et al. (2000) above the stability threshold (red line) when compared to Fig. 6.

On the other hand, the results in Fig. 7 also indicate that there are some reservations regarding the experimental data based on real human test subjects. For example, Lind et al. (2004) noted that these two datasets should not be aggregated in the application process, because these datasets are too small, not random and consequently not representative enough. In addition, Abt et al. (1989) reported that their experiments had some constraints, such as optimal experiment conditions, the presence of the safety equipment, healthy test subjects and the ability of the test subject to learn how to manoeuvre in the flow with time. Similar findings were reported by Karvonen et al. (2000), who noted that their experiments also had some shortcomings, such as excessive safety features, the use of survival suits, which increased the buoyancy and cross-sectional area of a person, and the use of a slippery surface. It is therefore reasonable to assume that these experiments did not represent the actual response of a person in the event of real-life flooding.

In general, an average person has probably never been directly faced with rising floodwaters, which means that such a person does not know how to readjust the body position in order to maintain stability for longer, as a real human test subject would after a few test runs (i.e. training). Furthermore, it is important to point out that not all people in the general population are healthy or physically fit and are not therefore able to adequately 
face the dangers due to flooding. This being the case, including only healthy and relatively young test subjects in the experimental studies leads to safety criteria that exclude some of the most vulnerable groups of the general population, such as frail and/or elderly citizens, and people with physical disabilities. Finally, one of the key factors that have a major effect on human stability in floodwaters is human psychology. If a human test person is attached with safety ropes, and therefore feels completely safe, then the psychological factors, such as shock or fear, do not play a significant role in maintaining or losing stability in floodwaters. However, the psychological factors are sometimes even more influential than physical ability. For example, in the study presented by Cox et al. (2004) two child test subjects were similar in size and thus should have had similar safety characteristics. However, as these two child test subjects were of different age and physiological development, they had differing safety characteristics. This highlights the importance of demographic and psychological characteristics, as they can have a significant impact on a person's response time and consequently on a person's ability to adequately react to the dangers due to flooding. Therefore, it is reasonable to conclude that any stability thresholds based on experimental data collected using real human test subjects could be misleading and could lead to hazardous and unsafe situations in the case of a reallife flooding (Chanson et al. 2014). This being the case, the predictive ability of both methods was also validated against the experimental data of Xia et al. (2014).

As mentioned, Xia et al. (2014) used a scaled human body (i.e. a dummy) for their experiments. This meant that the scaled human body could not readjust its position or learn how to manoeuvre itself in the flow with time, and it could not be influenced by any sort of safety feature. This being the case, the experimental results obtained in this study tend to be more conservative from the flood risk point of view when compared to the experimental data obtained in the studies using real human test subjects (Xia et al. 2014). Figure 8 shows a comparison of the flood hazard prediction ability of the two methods using the experimental data of Xia et al. (2014). The blue circles identify the conditions when stability was lost due to the toppling instability mechanism, i.e. the flow conditions which led to instability of the human model due to the momentum. In Fig. 8, it can be seen that the empirically derived method classified the majority of the data as of low hazard, which indicates that the empirically derived method generally under-predicts the flood hazard indices. This is probably due to the fact that the experimental data of Abt et al. (1989) and Karvonen et al. (2000) were used in the derivation process for the empirical method, and therefore the ability of the test subjects to learn how to manoeuvre in the flow is incorporated in the empirically derived method (Cox et al. 2010). However, as mentioned earlier this means that the flood hazard assessment with the empirically derived method tends to be too optimistic regarding safety. Furthermore, it can also be seen that the empirically derived method showed a higher flood hazard index (i.e. moderate hazard) for the tests where the stability was lost in the sub-critical flow regime, whereas almost all tests in which the stability was lost in the super-critical flow regime were classified as low hazard. This indicates that the empirically derived method, despite the potential shortcomings, still better assesses flood hazard indices for relatively slowly changing flow conditions than for the high Froude number flows, i.e. for the rapidly varying velocities that often occur with extreme flood events.

Figure 8 also shows that the physically based and experimentally calibrated method agreed well with the experimental observations, as 20 out of 46 experimental observations can be found above the stability threshold (red line), which indicated that stability was lost, and with the vast majority of the remaining experimental observations being in the relative proximity of the stability threshold, which indicated that the model was close to losing 
stability, i.e. was greatly endangered by the flow conditions. In Fig. 8, it can also be seen that the physically based and experimentally calibrated method adapts well to high Froude number flows, which are generally characterized with abrupt changes in the flow regime and often occur with extreme flood events. From the experimental observations 17 out of 31 in the super-critical flow regime can be found above the stability threshold (red line), while the remaining experimental observations in the super-critical flow regime are in the low hazard stability regime. Thus, the physically based and experimentally calibrated method assesses the flood hazard indices much better for super-critical flows when compared to the empirically derived method.

In summary, the comparisons of the two methods with the experimental data have shown that the physically based and experimentally calibrated method is highly adaptable to the characteristics of a particular human body, which allows more accurate assessment of flood hazard indices to be made when compared to the empirically based method. Furthermore, the physically based and experimentally calibrated method also generally agreed better with the observations which recorded the loss of stability in the super-critical flow regime when compared to the empirically based method. Therefore, the results obtained in the comparisons with the experimental observations suggest that the methods derived from a mechanics-based analysis, such as the physically based and experimentally calibrated method considered in this study, would be more appropriate for flood hazard assessment of extreme flood events than the classically used methods, such as the empirically based method considered herein.

\subsection{Comparisons of the flood hazard indices assessed using the two methods in the numerical simulations of extreme flood events}

Two extreme flood events were considered herein: the 2010 Kostanjevica na Krki large river flood and the 2007 Železniki flash flood. As the empirical method considered herein is based on the experimental data of Abt et al. (1989) and Karvonen et al. (2000) (e.g. real human body), the calibrating parameters $\alpha$ and $\beta$ used to calibrate the physically based and experimentally calibrated method for the numerical simulations of extreme flood events were also based on the same datasets, i.e. a real human body (see Table 2). This being the case, neither of the considered methods were ideal in terms of being able to predict accurately to the calibration dataset.

Figures 9 and 11 show a comparison between the empirically derived and the physically based and experimentally calibrated flood hazard assessment method for the 2010 Kostanjevica na Krki extreme river flood event. A step-by-step presentation of the assessed flood hazard shows that both methods were assessing a relatively similar degree of flood hazard for the first half of the simulation, i.e. for the first $36 \mathrm{~h}$ (see Fig. 9). This is not surprising, as the flood was gradually increasing in intensity during the first half of the simulation period and therefore both methods could easily replicate the relatively gradual changes in the flow regime. However, the flooding becomes much more intense during the second part of the simulation, i.e. over the last $36 \mathrm{~h}$ (see Fig. 10). This clearly reflects on the flood hazard assessment predictions, as it can be seen in Fig. 11. In the last $36 \mathrm{~h}$ of the 2010 Kostanjevica na Krki flood simulation scenario, the physically based and experimentally calibrated method assessed a higher degree of flood hazard at every time mark when compared to the flood hazard assessment obtained with the empirically derived method. These results were expected, as the physically based and experimentally calibrated method is based on being linked to the momentum of the flow, which is proportional to the square of the velocity, as compared to the empirically derived formulation, which is far less 
Degree of flood hazard

$\begin{array}{lll}\text { low } & \text { moderate } & \text { significant } \\ & \mathbf{t}=\mathbf{1 2} \mathbf{h}\end{array}$
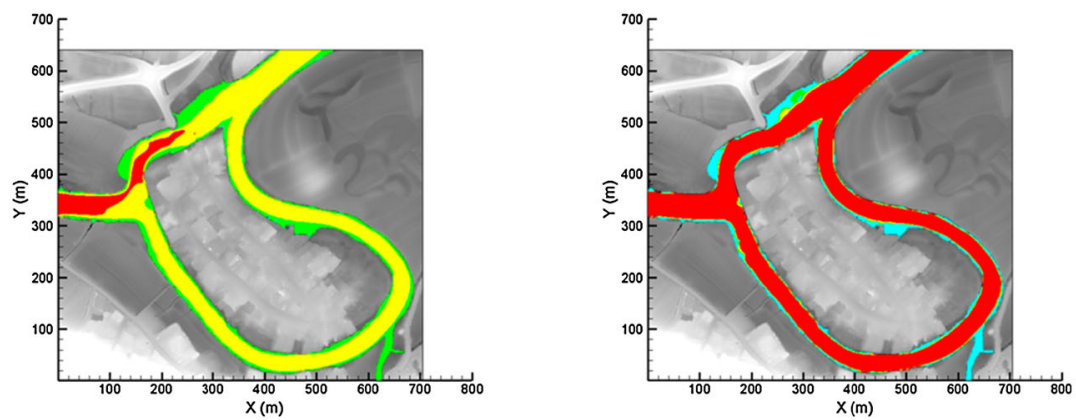

$\mathbf{t}=\mathbf{2 4} \mathbf{h}$
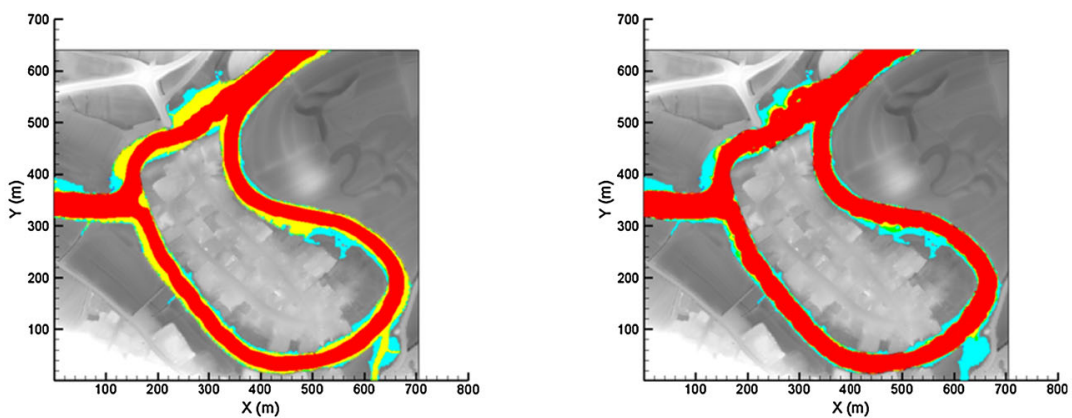

$\mathbf{t}=36 \mathrm{~h}$
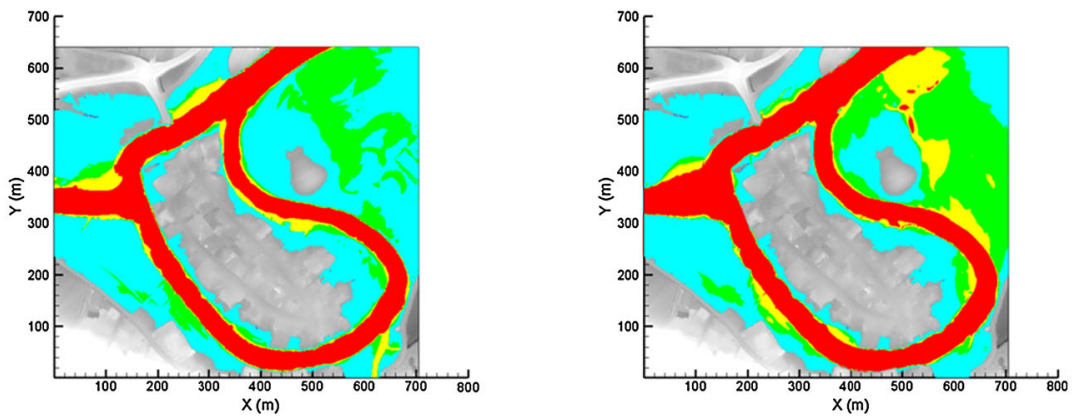

Fig. 9 Flood hazard rating at 12, 24 and $36 \mathrm{~h}$ after the start of the 2010 Kostanjevica na Krki flood simulation according to the empirically derived method (left) and the physically based experimentally calibrated method (right)

sensitive to the velocity of the flood flow. These results suggest that the empirically derived flood hazard assessment method cannot accurately assess the degree of flood hazard for high Froude number flows, or violent flood events, and that flood hazard assessment methods based on a mechanics-based analysis, such as the physically based and 
Froude number: $\quad 0.10 .20 .30 .40 .50 .60 .70 .80 .91$

$$
\mathrm{t}=42 \mathrm{~h}
$$

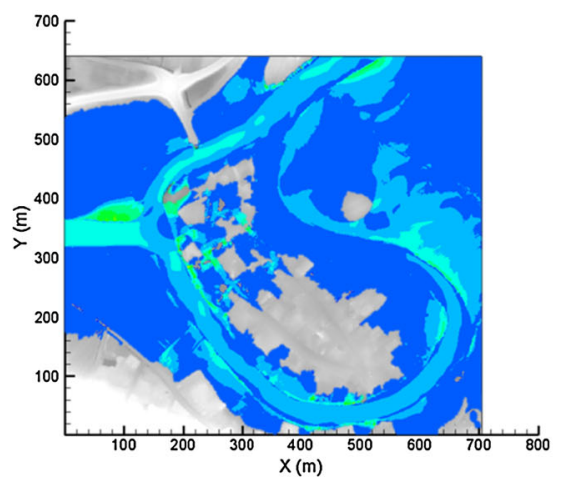

$$
\mathbf{t}=\mathbf{5 4} \mathrm{h}
$$

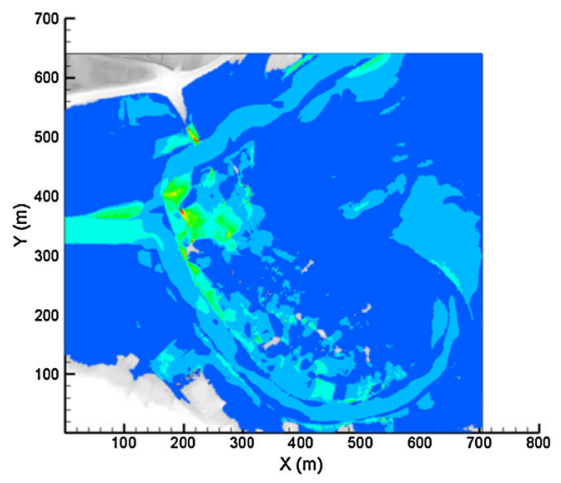

$t=66 \mathrm{~h}$

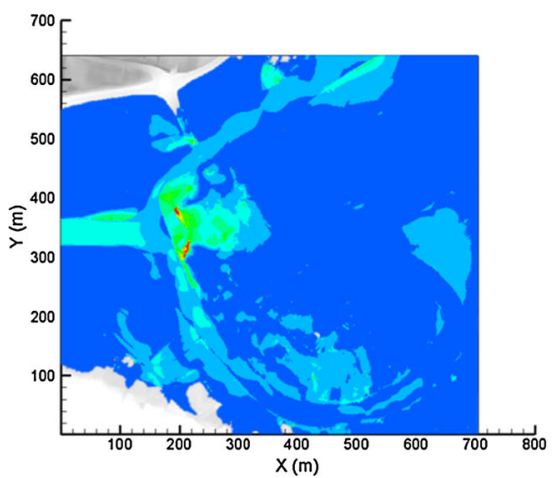

$$
\mathrm{t}=48 \mathrm{~h}
$$

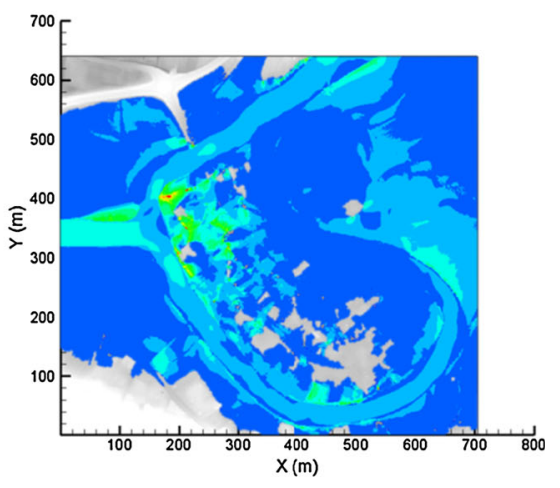

$\mathbf{t}=60 \mathrm{~h}$
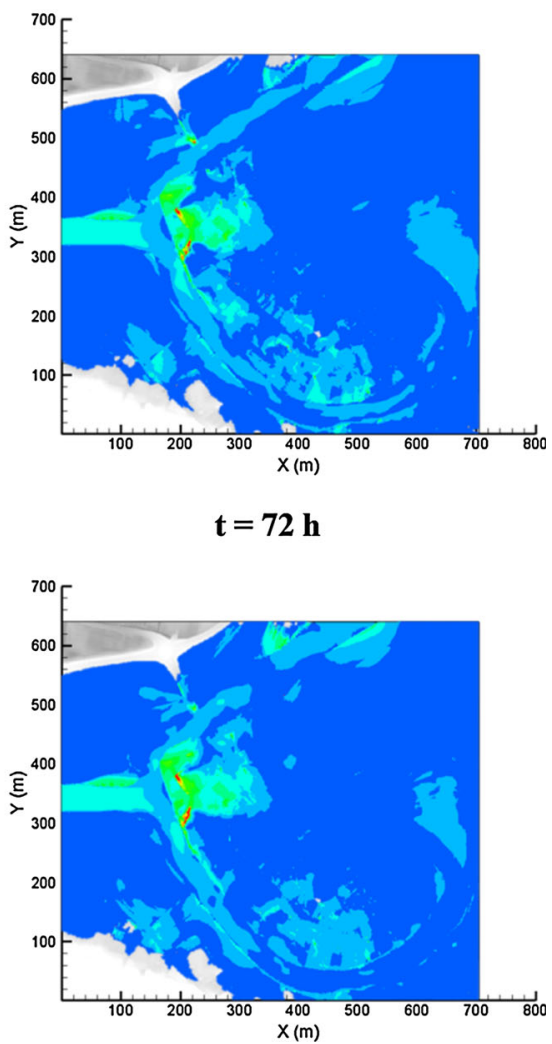

Fig. 10 Froude number for the last $36 \mathrm{~h}$ of the 2010 Kostanjevica na Krki flood simulation 


\section{Degree of flood hazard}

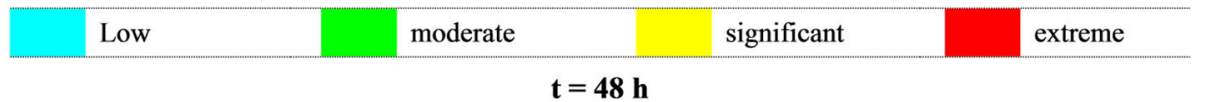
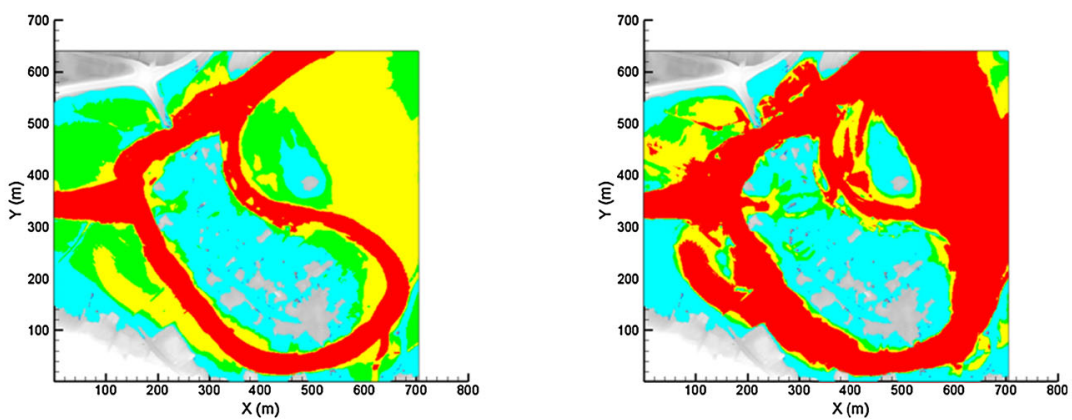

$\mathbf{t}=60 \mathrm{~h}$
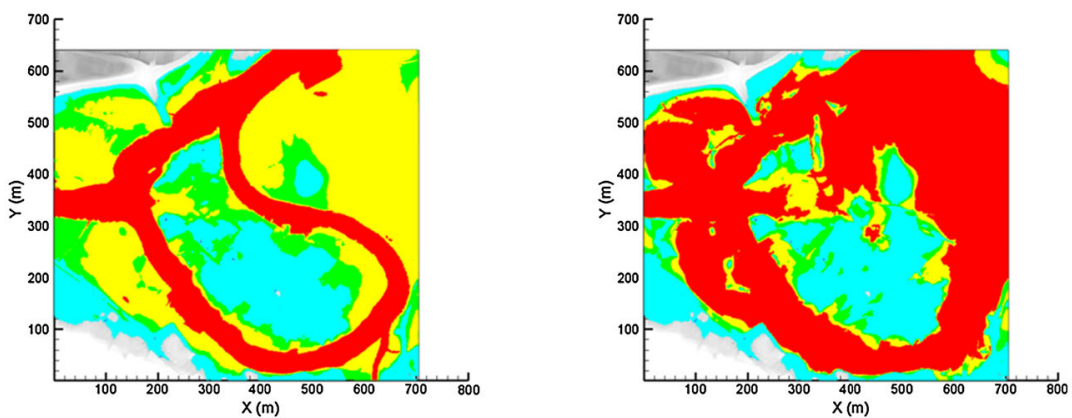

$\mathbf{t}=72 \mathrm{~h}$
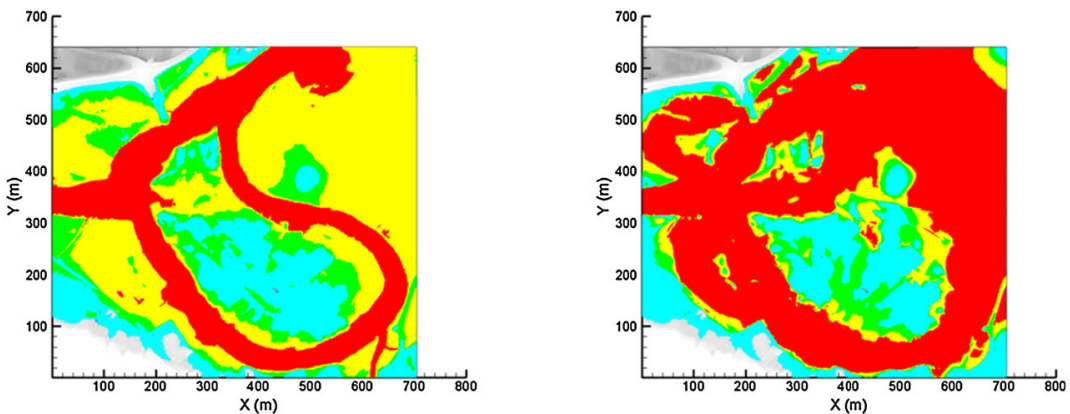

Fig. 11 Flood hazard rating at 48, 60 and $72 \mathrm{~h}$ after the start of the 2010 Kostanjevica na Krki flood simulation according to the empirically derived method (left) and the physically based experimentally calibrated method (right)

experimentally calibrated method considered herein, should be used for flood hazard assessment of extreme flood events and where the flood velocity of flow is relatively high (Fig. 12). 
Froude number: $\quad 0.10 .20 .30 .40 .50 .60 .70 .80 .91$

\section{$\mathbf{t}=\mathbf{2 0} \min$}

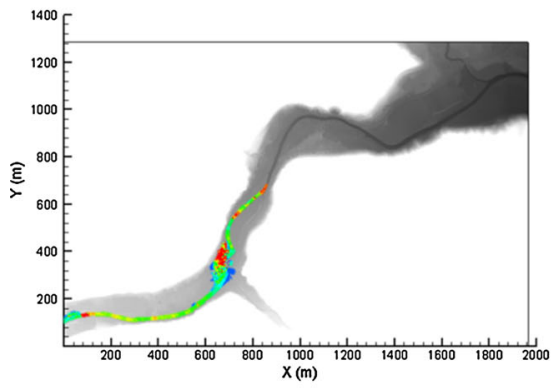

$\mathbf{t}=\mathbf{6 0} \min$

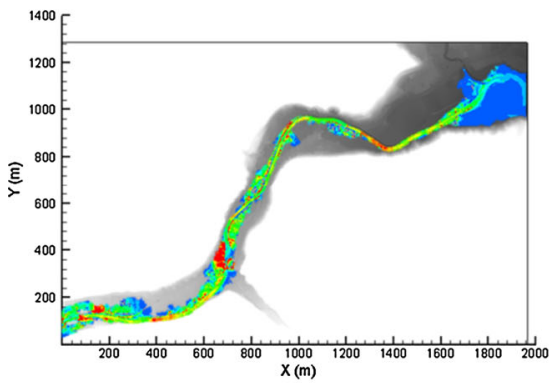

$\mathbf{t}=\mathbf{1 0 0} \min$

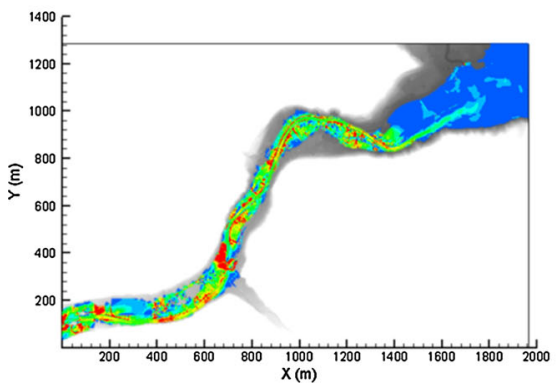

$\mathbf{t}=\mathbf{4 0} \min$

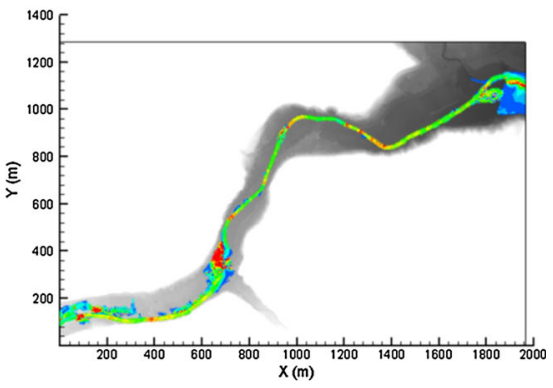

$\mathbf{t}=\mathbf{8 0} \min$

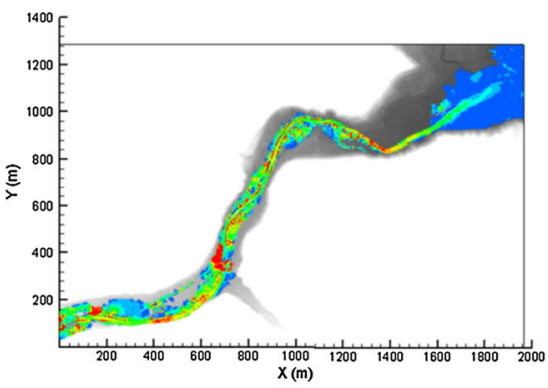

$t=120 \min$

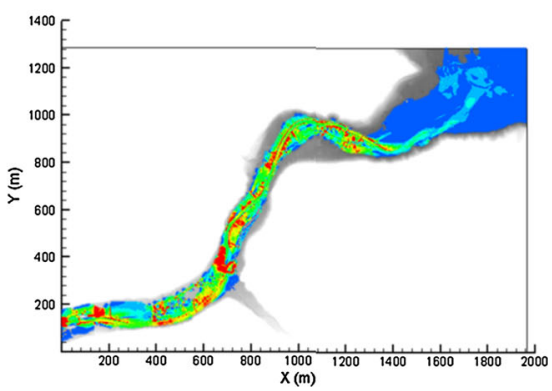

Fig. 12 Froude number for the 2007 Železniki flood simulation

Figures 13 and 14 show a comparison between the empirically derived, and the physically based and experimentally calibrated flood hazard assessment method for the 2007 Železniki flash flood event. Step-by-step presentation of the assessed flood hazard shows that the results from the two selected methods differ from the beginning of the flood simulation. In Figs. 13 and 14, it can be seen that the physically based and experimentally calibrated method predicted higher flood hazard indices at every stage of the simulation when compared to the results obtained with the empirically derived method. These results 
Degree of flood hazard

\begin{tabular}{l|l|l|l|} 
Low & moderate & significant & extreme \\
\hline
\end{tabular}
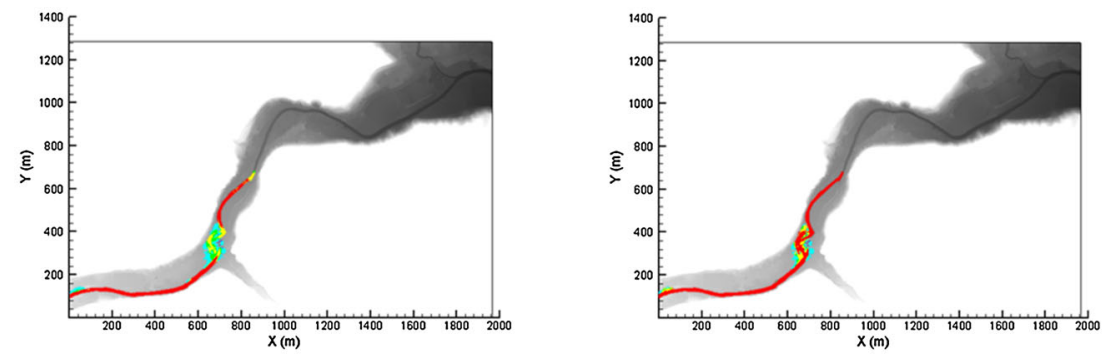

\section{$\mathbf{t}=\mathbf{4 0} \min$}
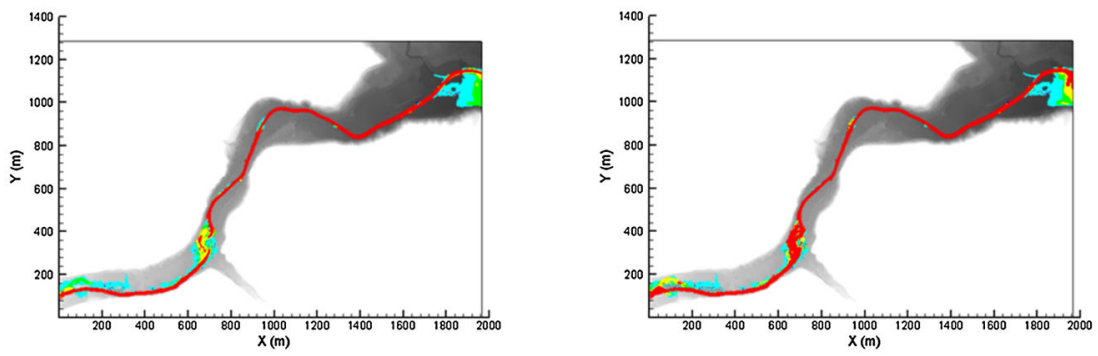

\section{$\mathbf{t}=60 \mathrm{~min}$}
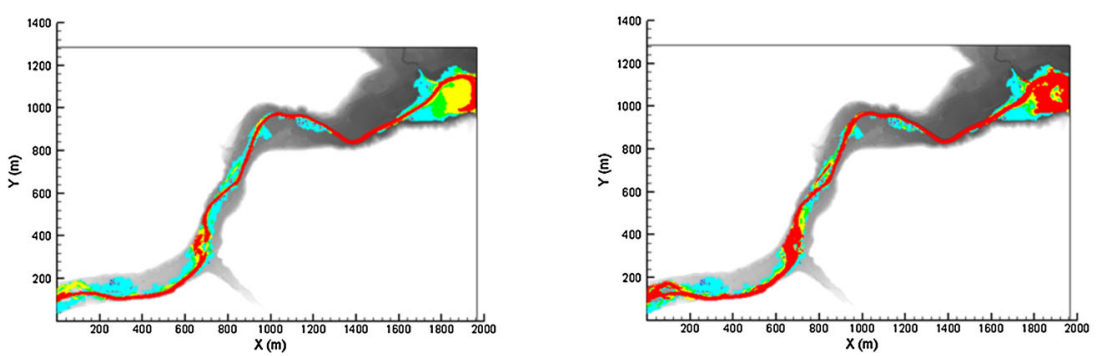

Fig. 13 Flood hazard rating at 20,40 and $60 \mathrm{~min}$ after the start of the 2007 Železniki flash flood simulation according to the empirically derived method (left) and the physically based method and experimentally calibrated method (right)

were expected, as the physically based and experimentally calibrated method is much more influenced by higher velocities and momentum, associated with higher Froude number flows and which occur more frequently with flash floods (see Fig. 12). On the other hand, the empirically derived method is rather a simple approach for flash flood events, or other extreme flood events where the Froude number is relatively high, with the method being a function of the velocity only, vis-à-vis the square of the velocity for the physics based method. All in all, these results agree well with the results obtained for the Kostanjevica na Krki extreme river flood event and further indicate that flood hazard assessment methods based on a mechanics-based analysis, such as the physically based and experimentally 
Degree of flood hazard

\begin{tabular}{l|l|l|l|} 
Low & moderate & significant & extreme \\
\hline
\end{tabular}
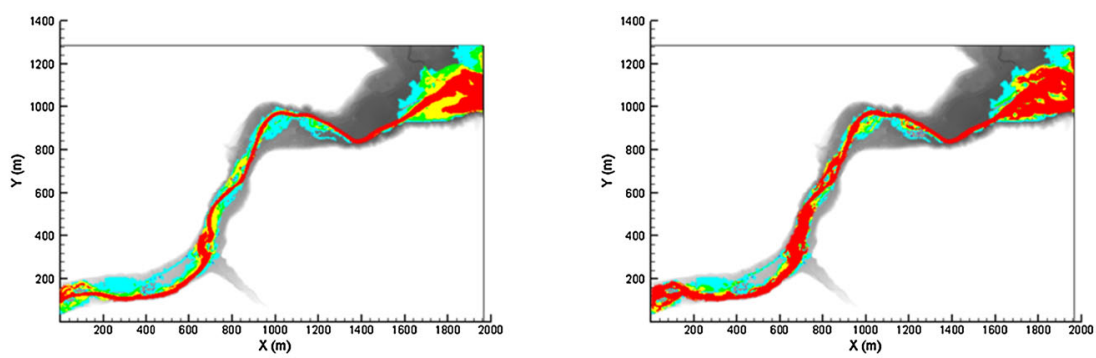

\section{$\mathbf{t}=\mathbf{1 0 0} \min$}
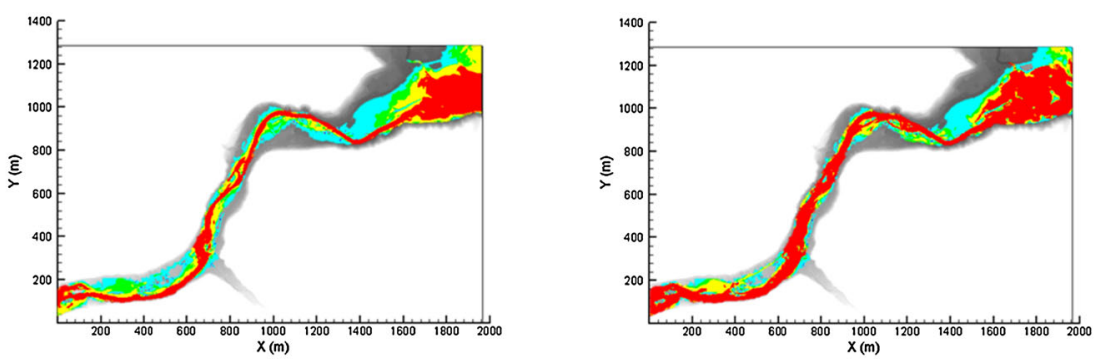

\section{$\mathrm{t}=120 \mathrm{~min}$}
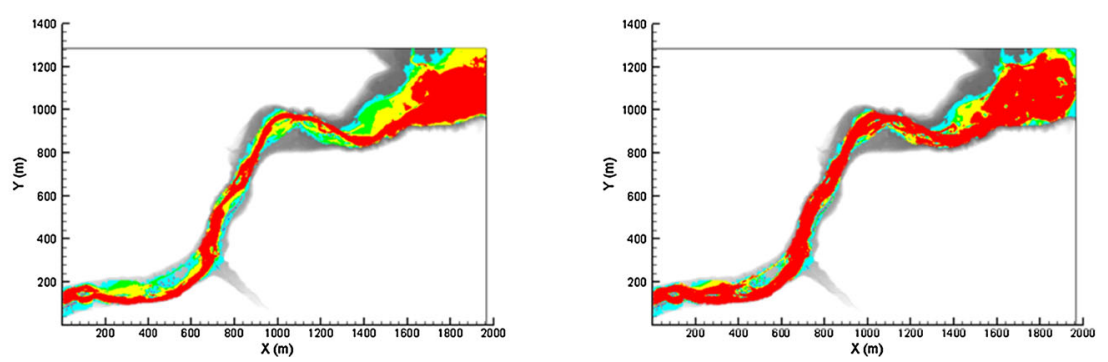

Fig. 14 Flood hazard rating at 80, 100 and $120 \mathrm{~min}$ after the start of the 2007 Železniki flash flood simulation according to the empirically derived method (left) and the physically based experimentally calibrated method (right)

calibrated method considered herein, should be used for flood hazard assessment of extreme flood events.

It should be again noted that the empirically derived flood hazard assessment method presented herein is well established in the UK and that flood hazard maps issued by the governing authorities in the UK, e.g. DEFRA, are based on this criterion. The formulae based on empirical or quasi-theoretical studies, such as the empirically derived method considered in this study, are suitable and accurate for low land floods, with a low Froude number. However, for flood events where the velocity conditions change rapidly and the Froude numbers are relatively large, such as during flash floods or extreme river floods (see 
Figs. 10 and 12), these methods fail to accurately predict flood hazard indices. Instead, a flood hazard assessment in areas prone to flash flooding, or in areas known for large-scale and violent river flooding, should be undertaken using flood hazard assessment methods based on a mechanics-based analysis, because these methods are able to efficiently take into account rapid changes in the flow regime and enable a rapid assessment of the degree of flood hazard risk in a short time period.

Although the differences between the tested two flood hazard assessment methods might seem insignificant for some cases, the difference in the accuracy could be a crucial factor when it comes to real-life rescue actions and the need to decide on the priority areas for the emergency services, etc. The rescue services can acquire much more accurate and meaningful information from the step-by-step presentation of the development of a potential flood event, or from a video simulation of flood propagation, using the physically based approach for flood hazard prediction, as compared to standard flood hazard maps. This is particularly important in the case of violent flood events, such as flash flooding, as it allows such flood hazards to be more accurately determined and for the emergency services, etc., to determine how much time they have for a rescue operation, as well as determining the optimum rescue routes from a flood prone region. Therefore, flood hazard assessment methods based on a mechanics-based analysis, such as the physically based and experimentally calibrated method considered herein, could provide an additional response time and more efficient deployment of the rescue services, particularly during the most critical stages of flooding.

Even though the use of more sophisticated flood hazard assessment methods can improve the prediction of flood hazard indices, the precondition for an adequate flood hazard assessment is still an accurate flood inundation model. Firstly, there is a need to use appropriate flood inundation models and flood risk assessment techniques when modelling specific flood events, such as flash flooding (Kvočka et al. 2015). Secondly, an important factor in flood inundation modelling, and thus flood hazard assessment processes, is also the selected grid size. In the study conducted by Smith and Wasko (2012), it was shown that model resolutions of up to $10 \mathrm{~m}$ were adequate for representing peak flood levels, whereas model resolutions of $2 \mathrm{~m}$ or less were required to represent the complex flow patterns in urban areas. This being the case, a change in the grid resolution can have a significant effect on the predicted flow velocities, flow directions, flow discharge distributions and ultimately on the prediction of flood hazard indices (Smith and Wasko 2012). Therefore, any flood hazard assessment should not be focused exclusively on the selection of an appropriate flood hazard assessment method, but it should also take into account the complexity of the modelling area and the nature of the considered flood flow (e.g. the expected hydraulic characteristics of the considered flood flow).

\section{Conclusions}

In this paper, we have investigated two very different flood hazard assessment methods and analysed the different predictions for flood hazard assessment in the areas where extreme flood events are likely to occur, i.e. in areas prone to flash flooding or large river flooding. Two flood hazard assessment methods were tested, including: (1) a widely used, empirically derived method and (2) a recently introduced, physically based and experimentally calibrated method. The two flood hazard assessment methods considered herein were first evaluated against three different experimental datasets, including two datasets based on 
testing real human subjects and one dataset based on experiments using model human bodies, and later used to assess the flood hazard rating for two extreme flood events, i.e. the 2010 Kostanjevica na Krki extreme river flood event and the 2007 Železniki flash flood.

The results obtained in this study show that in areas prone to extreme flooding, the flood hazard indices should be predicted based on methods derived from a mechanics-based analysis, such as the physically based and experimentally calibrated method considered in this study. Such methods have a number of benefits since they: (1) consider all of the physical forces acting on a human body in floodwaters, (2) are able to efficiently take into account rapid changes in the flow (or velocity) regime, something that usually occurs during flash flooding or large river flooding, and (3) are very sensitive to significant changes locally in the hydrodynamic conditions of the flow. Furthermore, the recently introduced flood hazard assessment methodologies derived from a mechanics-based analysis, such as the method by Xia et al. (2014) considered herein, or the methodology proposed by Milanesi et al. (2015), can be adjusted to: (1) a specific body type, such as Asian, Caucasian or African-American, (2) a specific region, such as Europe, USA or China and (3) a specific sub-population group, such as men, women or children. This being the case, the criterion derived from a mechanics-based analysis can provide valuable information on the response time and enable more efficient rescue operations, as they are highly adaptable to extreme flood conditions and human body characteristics, and can therefore provide an accurate real-time assessment of the risk to people caused by real-time extreme flooding.

Even though extreme flood events rarely occur, they are the most devastating and lifethreatening form of all natural hazards. This being the case, there is a need to improve our knowledge of predicting extreme weather events, extreme flooding processes and flood hazard assessment methodologies, in particular for areas prone to extreme flooding. The development of recently introduced physically based methods, such as the method considered herein or the methodology presented by Milanesi et al. (2015), has shown the importance of the physical interpretation and the need for a realistic description of the processes that influence human stability in floodwaters. However, future research in the field of flood hazard assessment should not focus solely on the hydraulic parameters that influence the human stability in floodwaters, but should also: (1) include the demographic and psychological characteristics of the general population in improved, or newly proposed, flood hazard assessment criteria, and (2) consider other indirect parameters (such as grid resolution) in the flood hazard assessment process. As indicated herein, and also by other authors, these characteristics are sometimes even more important than the hydraulic characteristics of the flood flow and therefore should be considered in more detail in future studies. Although extreme flooding cannot be prevented, more can be done in the future to limit the consequence of these flood events, especially by using appropriate flood inundation prediction models and improved flood hazard assessment methodologies.

Acknowledgments This research project was funded by High Performance Computing (HPC) Wales and Fujitsu, part funded by the European Regional Development Fund and European Social Fund. The bathymetric data for the Kostanjevica na Krki and the Železniki study were provided by the Slovenian Environment Agency. The contribution of all of these organizations is gratefully acknowledged. The authors would especially like to thank Professor Junqiang Xia, Wuhan University, for providing the experimental data and all of his additional help. Finally, the authors would also like to thank Gergana Stefanova Nikolova, Žiga Šebenik and Špela Tomažič for their comments and assistance.

Open Access This article is distributed under the terms of the Creative Commons Attribution 4.0 International License (http://creativecommons.org/licenses/by/4.0/), which permits unrestricted use, distribution, 
and reproduction in any medium, provided you give appropriate credit to the original author(s) and the source, provide a link to the Creative Commons license, and indicate if changes were made.

\section{References}

Abt SR, Wittier RJ, Taylor A, Love DJ (1989) Human stability in a high flood hazard zone. J Am Water Resour As 25:881-890

Alfieri L, Burek P, Feyen L, Forzieri G (2015) Global warming increases the frequency of river floods in Europe. Hydrol Earth Syst Sci 19:2247-2260

Amengual A, Homar V, Jaume O (2015) Potential of a probabilistic hydrometeorological forecasting approach for the 28 September 2012 extreme flash flood in Murcia, Spain. Atmos Res 166:10-23

Androulidakis YS, Kombiadou KD, Makris CV, Baltikas VN, Krestenitis YN (2015) Storm surges in the Mediterranean Sea: variability and trends under future climatic conditions. Dyn Atmos Oceans 71:56-82

Antico A, Torres ME, Diaz HF (2016) Contributions of different time scales to extreme Paraná floods. Clim Dyn 46(11):3785-3792

Ashley ST, Ashley WS (2008) Flood fatalities in the United States. J Appl Meteorol Climatol 47:805-818

Beniston M (2009) Trends in joint quantiles of temperature and precipitation in Europe since 1901 and projected for 2100. Geophys Res Lett 36:L07707

Bergman N, Sholker O, Roskin J, Greenbaum N (2014) The Nahal Oz Reservoir dam-break flood: geomorphic impact on a small ephemeral loess-channel in the semi-arid Negev Desert, Israel. Geomorphology 210:83-97

Bouilloud L, Delrieu G, Boudevillain B, Borga M, Zanon F (2009) Radar rainfall estimation for the postevent analysis of a Slovenian flash-flood case: application of the Mountain Reference Technique at C-band frequency. Hydrol Earth Syst Sci 13:1349-1360

Brakenridge G (2012) Global Active Archive of Large Flood Events, Dartmouth Flood Observatory, University of Colorado [Online]. http://floodobservatory.colorado.edu/Archives/index.html

Breilh J-F, Bertin X, Chaumillon É, Giloy N, Sauzeau T (2014) How frequent is storm-induced flooding in the central part of the Bay of Biscay? Glob Planet Change 122:161-175

Bruwier M, Erpicum S, Pirotton M, Archambeau P, Dewals B (2015) Assessing the operation rules of a reservoir system based on a detailed modelling chain. Nat Hazards Earth Syst Sci 15:365-379

Chanson H (2004) Hydraulics of open channel flow. Heinemann, Butterworth

Chanson H, Brown R, Mcintosh D (2014) Human body stability in floodwaters: the 2011 flood in Brisbane CBD. In: Proceedings of the 5th international symposium on hydraulic structures: engineering challenges and extremes, 2014. The University of Queensland

Chau VN, Holland J, Cassells S, Tuohy M (2013) Using GIS to map impacts upon agriculture from extreme floods in Vietnam. Appl Geogr 41:65-74

Cox R, Yee M, Ball J (2004) Safety of people in flooded streets and floodways. National conference on hydraulics in water engineering, Engineers Australia

Cox R, Shand T, Blacka M (2010) Revision project 10: appropriate safety criteria for people. Stage 1 report. Australian rainfall and runoff. Water Research Laboratory, The University of New South Wales

Davis SF (1984) TVD finite difference schemes and artificial viscosity. National Aeronautics and Space Administration, Langley Research Center, Hampton, Virginia

Di Baldassarre G, Montanari A, Lins H, Koutsoyiannis D, Brandimarte L, Blöschl G (2010) Flood fatalities in Africa: from diagnosis to mitigation. Geophys Res Lett 37:L22402

Drillis R, Contini R, Bluestein M (1964) Body segment parameters. Artif Limbs 8:44-66

Duffaut P (2013) The traps behind the failure of Malpasset arch dam, France, in 1959. J Rock Mech Geotech Eng 5:335-341

Foster D, Cox R (1973) Stability of children on roads used as floodways. Technical Report No.73/13. Water Research Laboratory of the University of New South Wales, Manly Vale, Australia

Foudi S, Osés-Eraso N, Tamayo I (2015) Integrated spatial flood risk assessment: the case of Zaragoza. Land Use Policy 42:278-292

Foulds SA, Macklin MG, Brewer PA (2014) The chronology and the hydrometeorology of catastrophic floods on Dartmoor, South West England. Hydrol Process 28:3067-3087

Godunov SK (1959) A difference method for numerical calculation of discontinuous solutions of the equations of hydrodynamics. Matematicheskii Sbornik 89:271-306

Grillakis M, Tsanis I, Koutroulis A (2010) Application of the HBV hydrological model in a flash flood case in Slovenia. Nat Hazards Earth Syst Sci 10:2713-2725 
Güneralp B, Güneralp İ, Liu Y (2015) Changing global patterns of urban exposure to flood and drought hazards. Glob Environ Change 31:217-225

Harten A (1983) High resolution schemes for hyperbolic conservation laws. J Comput Phys 49:357-393

Herget J, Kapala A, Krell M, Rustemeier E, Simmer C, Wyss A (2015) The millennium flood of July 1342 revisited. Catena 130:82-94

Hunter N, Bates P, Neelz S, Pender G, Villanueva I, Wright N, Liang D, Falconer RA, Lin B, Waller S (2008) Benchmarking 2D hydraulic models for urban flood simulations. In: Proceedings of the institution of civil engineers: water management, 2008. Thomas Telford (ICE publishing) pp 13-30

Ishigaki T, Baba Y, Toda K, Inoue K (2005) Experimental study on evacuation from underground space in urban flood. In: Proceedings of 31st IAHR Congress on CD-ROM, Seoul, 2005

Ishigaki T, Kawanaka R, Onishi Y, Shimada H, Toda K, Baba Y (2009) Assessment of safety on evacuating route during underground flooding. In: Advances in water resources and hydraulic engineering. Springer, Berlin, pp 141-146

Jonkman SN (2005) Global perspectives on loss of human life caused by floods. Nat Hazards 34:151-175

Jonkman S, Penning-Rowsell E (2008a) Human instability in flood flows. J Am Water Resour As 44:1208-1218

Jonkman SN, Penning-Rowsell E (2008b) Human instability in flood flows. J Am Water Resour As 44:1208-1218

Karvonen R, Hepojoki H, Huhta H, Louhio A (2000) The use of physical models in dam-break flood analysis, Development of Rescue Actions Based on Dam-Break Flood Analysis (RESCDAM). Final report of Helsinki University of Technology. Finnish Environment Institute

Kaźmierczak A, Cavan G (2011) Surface water flooding risk to urban communities: analysis of vulnerability, hazard and exposure. Landsc Urban Plan 103:185-197

Keller RJ, Mitsch B (1993) Safety aspects of the design of roadways as floodways. Urban Water Research Association of Australia, Australia

Kobold M (2011) Comparison of floods in September 2010 with registered historic flood events (in Slovenian). Ujma 25:48-56

Kobold M, Sušnik M, Robič M, Ulaga F, Lalić B (2008) Hydrological analysis of high waters and flash floods occurred in September 2007 in Slovenia. In: IOP conference series: earth and environmental science, 2008. IOP Publishing, 012008

Koks EE, Jongman B, Husby TG, Botzen WJW (2015) Combining hazard, exposure and social vulnerability to provide lessons for flood risk management. Environ Sci Policy 47:42-52

Kundzewicz ZW, Pińskwar I, Brakenridge GR (2013) Large floods in Europe, 1985-2009. Hydrol Sci J 58:1-7

Kvočka D, Falconer RA, Bray M (2015) Appropriate model use for predicting elevations and inundation extent for extreme flood events. Nat Hazards 79:1791-1808

Lax PD, Wendroff B (1960) Systems of conservation laws. Commun Pure Appl Math 13:217-237

Lenderink G, van Meijgaard E (2008) Increase in hourly precipitation extremes beyond expectations from temperature changes. Nat Geosci 1:511-514

Liang D, Falconer RA, Lin B (2006) Comparison between TVD-MacCormack and ADI-type solvers of the shallow water equations. Adv Water Resour 29:1833-1845

Liang D, Lin B, Falconer RA (2007a) A boundary-fitted numerical model for flood routing with shockcapturing capability. J Hydrol 332:477-486

Liang D, Lin B, Falconer RA (2007b) Simulation of rapidly varying flow using an efficient TVDMacCormack scheme. Int J Numer Meth Fluids 53:811-826

Liang D, Wang X, Falconer RA, Bockelmann-Evans BN (2010) Solving the depth-integrated solute transport equation with a TVD-MacCormack scheme. Environ Model Softw 25:1619-1629

Liang D, Xia J, Falconer RA, Zhang J (2014) On the refinement of a boundary-fitted shallow water model. Coast Eng J 56:1450001

Lind N, Hartford D, Assaf H (2004) Hydrodynamic models of human stability in a flood. J Am Water Resour As 40:89-96

Maccormack RW (1976) An efficient numerical method for solving the time-dependent compressible Navier-Stokes equations at high Reynolds number. NASA Ames Research Center, Moffett Field

Marchi L, Borga M, Preciso E, Sangati M, Gaume E, Bain V, Delrieu G, Bonnifait L, Pogačnik N (2009) Comprehensive post-event survey of a flash flood in Western Slovenia: observation strategy and lessons learned. Hydrol Process 23:3761-3770

Martínez Ibarra E (2012) A geographical approach to post-flood analysis: the extreme flood event of 12 October 2007 in Calpe (Spain). Appl Geogr 32:490-500

Milanesi L, Pilotti M, Ranzi R (2015) A conceptual model of people's vulnerability to floods. Water Resour Res 51:182-197 
Min S-K, Zhang X, Zwiers FW, Hegerl GC (2011) Human contribution to more-intense precipitation extremes. Nature 470:378-381

Mingham CG, Causon DM, Ingram D, Mingham CG, Causon DM, Ingram D (2001) A TVD MacCormack scheme for transcritical flow. Proc Inst Civ Eng: Water Marit Eng 148:167-175

Ministry of the Environment and Spatial Planning of the Republic of Slovenia (2015) LIDAR [Online]. http://evode.arso.gov.si/indexd022.html?q=node/12

Moussa R, Bocquillon C (2009) On the use of the diffusive wave for modelling extreme flood events with overbank flow in the floodplain. J Hydrol 374:116-135

Muis S, Güneralp B, Jongman B, Aerts JC, Ward PJ (2015) Flood risk and adaptation strategies under climate change and urban expansion: a probabilistic analysis using global data. Sci Total Environ 538:445-457

Neelz S, Pender G (2009) Desktop review of 2D hydraulic modelling packages. Environment Agency, Bristol

Nikolova GS, Toshev YE (2007) Estimation of male and female body segment parameters of the Bulgarian population using a 16-segmental mathematical model. J Biomech 40:3700-3707

Penning-Rowsell E, Floyd P, Ramsbottom D, Surendran S (2005a) Estimating injury and loss of life in floods: a deterministic framework. Nat Hazards 36:43-64

Penning-Rowsell E, Johnson C, Tunstall S, Tapsell S, Morris J, Chatterton J, Green C (2005b) The benefits of flood and coastal risk management: a handbook of assessment techniques. Middlesex University Press, London

Purwandari T, Hadi MP, Kingma NC (2011) A GIS modelling approach for flood hazard assessment in part of Surakarta city, Indonesia. Indones J Geogr 43:63-80

Ramsbottom D, Floyd P, Penning-Rowsell E (2003) Flood risks to people: Phase 1. R\&D Technical Report FD2317, Department for the Environment, Food and Rural Affairs (DEFRA), UK Environment Agency

Ramsbottom D, Wade S, Bain V, Hassan M, Penning-Rowsell E, Wilson T, Fernandez A, House M, Floyd P (2006) Flood risks to people: Phase 2. R\&D Technical Report FD2321/IR2, Department for the Environment, Food and Rural Affairs (DEFRA), UK Environment Agency

Raška P, Emmer A (2014) The 1916 catastrophic flood following the Bílá Desná dam failure: the role of historical data sources in the reconstruction of its geomorphologic and landscape effects. Geomorphology 226:135-147

Rojas R, Feyen L, Watkiss P (2013) Climate change and river floods in the European Union: socio-economic consequences and the costs and benefits of adaptation. Glob Environ Change 23:1737-1751

Rusjan S, Kobold M, Mikoš M (2009) Characteristics of the extreme rainfall event and consequent flash floods in W Slovenia in September 2007. Nat Hazards Earth Syst Sci 9:947-956

Russo B, Gómez M, Macchione F (2013) Pedestrian hazard criteria for flooded urban areas. Nat Hazards 69:251-265

Schröter K, Kunz M, Elmer F, Mühr B, Merz B (2015) What made the June 2013 flood in Germany an exceptional event? A hydro-meteorological evaluation. Hydrol Earth Syst Sci 19:309-327

Slovenian Environment Agency (2008) Viskoe vode in poplave 18. septembra 2007 (in Slovenian) [Online]. http://www.arso.gov.si/vode/poro\%C4\%8Dila\%20in\%20publikacije/Visoke\%20vode\%20in\%20poplave\% 2018.\%20septembra\%202007.pdf

Slovenian Environment Agency (2010a) Hidrološko porocilo o povodnji v dneh od 17. do 21. septembra 2010 (in Slovenian) [Online]. http://www.arso.gov.si/vode/poro\%C4\%8Dila\%20in\%20publikacije/ Poplave\%2017.\%20-\%2021.\%20september\%202010.pdf

Slovenian Environment Agency (2010b) Porocilo o izjemno obilnih padavinah od 16. do 19. septembra 2010 (in Slovenian) [Online]. http://meteo.arso.gov.si/uploads/probase/www/climate/text/sl/weather_ events/padavine_16-19sep10.pdf

Slovenian Environment Agency (2013) Povratne dobe velikih in malih pretokov za merilna mesta državnega hidrološkega monitoringa površinskih voda (in Slovenian) [Online]. http://www.arso.gov.si/vode/ podatki/Povratne\%20dobe\%20Qvk,Qnp.pdf

Smith G, Wasko C (2012) Revision Project 15: two dimensional simulations in urban areas-representation of buildings in 2D numerical flood models. In: Ball J (ed) Australian rainfall and runoff. Engineers Australia, Canberra

Takahashi S, Endoh K, Muro Z (1992) Experimental study on people's safety against overtopping waves on breakwaters. Rep Port Harb Inst 34:4-31

UN (2014) World Urbanizations prospects: the 2014 revision. Population Division of the Department of Economic and Social Affairs of the United Nations Secretariat, New York

UN (2015) World population prospects: the 2015 revision. Population Division of the Department of Economic and Social Affairs of the United Nations Secretariat, New York 
Xia J, Falconer RA, Lin B, Tan G (2011) Numerical assessment of flood hazard risk to people and vehicles in flash floods. Environ Model Softw 26:987-998

Xia J, Falconer RA, Wang Y, Xiao X (2014) New criterion for the stability of a human body in floodwaters. J Hydraul Res 52:93-104

Yee M (2003). Human stability in floodways. Undergraduate Honours Thesis, University of New South Wales

Zanon F, Borga M, Zoccatelli D, Marchi L, Gaume E, Bonnifait L, Delrieu G (2010) Hydrological analysis of a flash flood across a climatic and geologic gradient: the September 18, 2007 event in Western Slovenia. J Hydrol 394:182-197

Zhi-Yong W, Gui-Hua L, Zhi-Yu L, Jin-Xing W, Heng X (2013) Trends of extreme flood events in the Pearl River Basin during 1951-2010. Adv Clim Change Res 4:110-116 